\title{
PLANIFICACIÓN NUTRICIONAL PARA UN NADADOR AMATEUR
}

\section{Antonio Álvarez Estévez}

\section{Email: antoniodelaera@hotmail.com}

\section{RESUMEN:}

El objetivo de este trabajo es brindar una planificación sobre la correcta nutrición que debe de realizar un deportista amateur durante la temporada.

Para llevar a cabo este trabajo, escogimos a un alumno de $3^{\circ}$ de Grado de Ciencias de la Actividad Física y el Deporte de la Universidad de Huelva que compite en natación a nivel amateur como sujeto para la realización de la planificación.

Para la correcta elaboración de este proyecto es preciso hacer primero un planteamiento sobre las características del sujeto. Una vez conocidas las características se estableció los objetivos que se querían alcanzar durante los 4 periodos de la programación deportiva (pretemporada, competición, recuperación y lesión). Posteriormente y en relación estos objetivos, se planificó la alimentación en base a la intensidad en estos 4 periodos

En cuanto a los resultados se realizó un cuestionario de recuerdo de la dieta que realiza este sujeto durante 3 días antes de la planificación, las pautas generales de actuación y por ultimo 4 ejemplos de dietas por cada periodo.

PALABRAS CLAVE: Deporte, nutrición, macronutrientes, natación, amateur, dieta, planificación. 


\section{INTRODUCCIÓN}

La prueba que realizará nuestro sujeto será 200 metros crol y se realizará 17:00 de la tarde.

"La ingesta adecuada para el deportista, es la que mantiene un peso corporal adecuando para el óptimo rendimiento y maximiza los efectos del entrenamiento". (Martínez-Sanz, Urdampilleta, y Mielgo-Ayuso, 2013, p. 284).

Es por esto por lo que la nutrición tiene una enorme importancia en cualquier deportista. No obstante, la antropometría también tiene una gran importancia en la natación. Tener una buena antropometría ayuda al nadador en la realización del gesto de una forma rápida y eficiente.

Barbara et al. (2011) remite en su articulo que el gasto calorico al realizar natación varia entre 3,8 y 10 MET lo que en un adulto de $70 \mathrm{~kg}$ equivaldria a 266-700 kcal/h, teniendo en cuenta que 1 met equivale a 1 kcal por kilo de peso por hora.

Dependiendo de las horas que entrenará y la intensidad, el deportista gastará más o menos calorías por lo que la cantidad de macronutrientes variara. Según Vázquez, 2000 (citado por Hurtado, 2006) el gasto calórico de un nadador de elite de 18-25 años es de 50006000 kcal aunque tratándose de un nadador a nivel amateur la ingesta calórica disminuirá. Como norma general el porcentaje de macronutrientes es de $70-75 \%$ en hidratos de carbono, $10-15 \%$ de grasas y un 15-20\% en proteínas (Hurtado, 2006).

Según Segovia Martínez, López-Silvarrey Varel, Legido Arce y Calderón Montero (2000) la distancia de la prueba influye en el porcentaje de grasa corporal. Estos valores son superiores en nadadores de largas distancias debido a su aislamiento sobre el frio y les proporciona mayor flotabilidad. El exceso de grasa reduce la densidad corporal y les permite nadar en la superficie por lo que reducirían el rozamiento aumentando así la velocidad.

Esto no quiere decir que el exceso de grasa vaya a tener buenos resultados en natación, ya que solo será beneficioso para nadadores de resistencia o en el aprendizaje de la técnica de estilos, donde la flotabilidad facilita el aprendizaje. 


\section{METODOLOGÍA}

\subsection{Característica del sujeto.}

El sujeto con el que vamos a trabajar es un nadador amateur de 24años que competirá en la especialidad de $200 \mathrm{~m}$ crol, estudiante de $3^{\circ}$ de Grado de Ciencias de la Actividad Física y Deportiva de la Universidad de Huelva cuya estatura es de $170 \mathrm{~cm}$ y sus parámetros corporales son los siguientes:

\begin{tabular}{|c|c|}
\hline VARIABLE & KG \\
\hline Peso & 66,1 \\
\hline Masa grasa & 14 \\
\hline Masa libre de grasa & 52.1 \\
\hline Masa muscular & 13.9 \\
\hline Masa celular & 34.4 \\
\hline Agua corporal total & 38.2 \\
\hline Agua intracelular & 24 \\
\hline Agua extracelular & 14.2 \\
\hline
\end{tabular}

Las características cineantropométricas del nadador son: ser alto, ligero, de hombros anchos, extremidades muy largas con gran potencia y fuerza. Donde suelen desarrollar una gran masa muscular es sobre la mitad superior del cuerpo. Los hombres suelen poseer un somatotipo medio ectomesoformo. (Martínez-Sanz et al. 2006). Nuestro deporstia tiene la siguiente somatocarta 


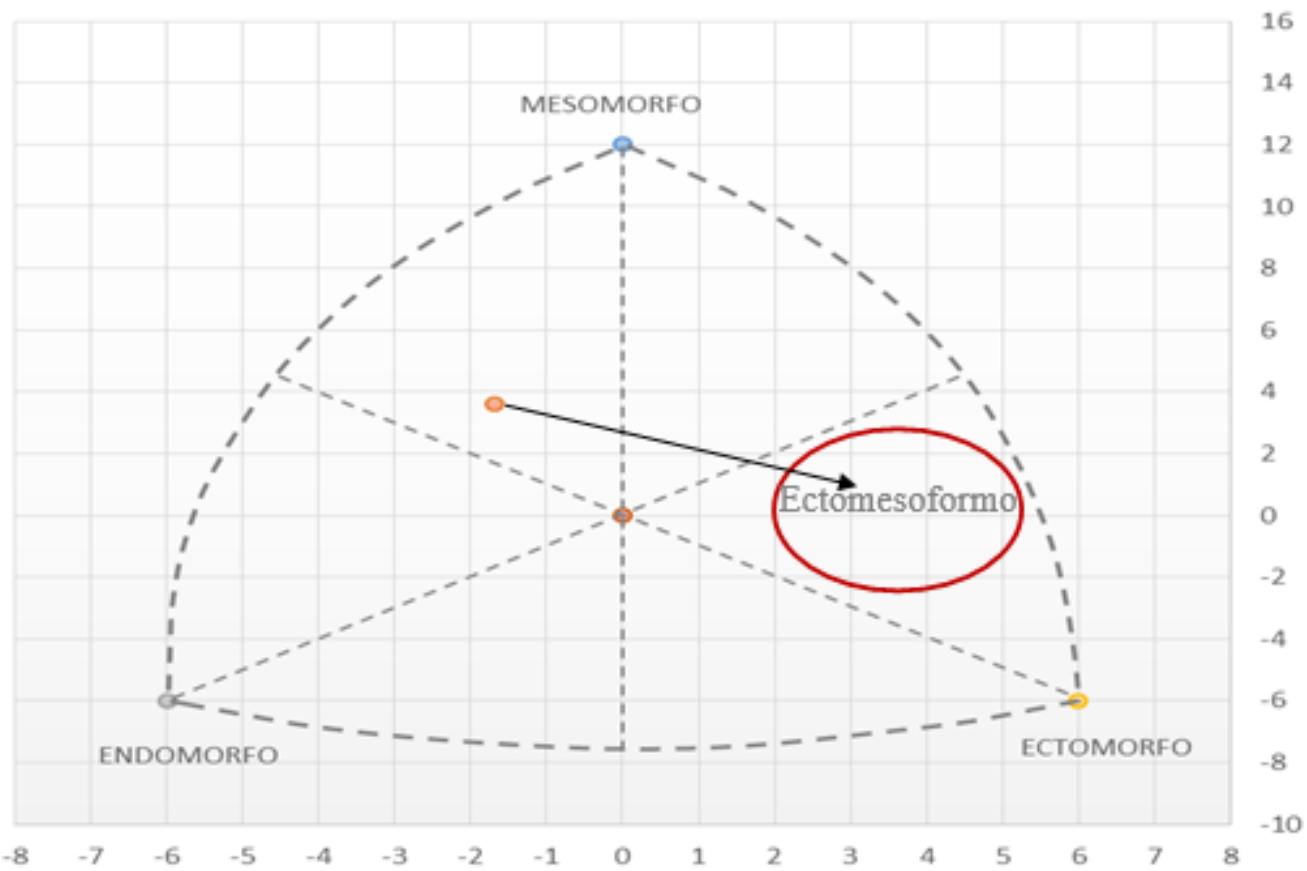

Esta somatocarta nos muesta que nuestro individuo posee un somatotipo mesomorfo endomorfo por lo que tendremos que llegar a unos valores cercanos al somatotipo medio ectomesoformo que es el propio de los nadadores.

\subsection{Objetivos.}

\subsubsection{Pretemporada.}

1. Llegar a un estado de forma ideal para afrontar toda la competición al máximo rendimiento posible.

2. Aumentar la composición corporal.

3. Aumentar los niveles de glucógeno.

4. Obtener una hidratación idónea.

\subsubsection{Competición.}

1. Tener el mayor porcentaje de reservas energéticas necesarias para acabar la prueba con el mayor éxito posible.

2. Tener una hidratación idónea para mantener estables los niveles de agua y electrolitos en el cuerpo.

3. Recuperar los niveles de glucógeno gastados durante la competición.

\subsubsection{Recuperación.}


1. Mantener la composición corporal ganada durante la temporada.

2. Mantener los niveles de glucógeno obtenidos.

3. Conseguir una buena hidratación.

\subsubsection{Proceso de lesión.}

1. Mantener la composición corporal conseguida hasta el momento.

\subsection{Planificación de los $\mathbf{4}$ estadios.}

Antes de planificar la ingesta calorica debemos de tener en cuenta que un $10 \%$ de las kcal ingeridas en una alimentacion variadad de macronutrientes son gastadas por el organismo en el proceso de la termogenesis (Obregón, 2009).

Todas las ingestas posteriormente descritas han sido aumentadas en este \%.

\subsubsection{Pretemporada.}

La alimentación en esta etapa debe de ser abundante en carbohidratos de rápida digestión para reponer el glucógeno muscular y hepático. Para que esto ocurra es necesario tomar estos alimentos 3 horas antes del inicio del entrenamiento. (Ramírez, 2006). También será necesario un buen aporte hiperproteico y normograso.

Además este aporte de carbohidratos nos ayudara a aumentar el nivel de masa corporal que buscamos en el deportista.

En la natación existe deshidratación por sudoración, aunque sea menos perceptible que en los deportes de tierra, por lo que será conveniente que el deportista beba agua. Beberán en cada descanso que hagan en las cantidades que ellos vean convenientes.

En pretemporada se alternará días en la piscina y en el gimnasio para el aumento de la fuerza, la potencia y la musculatura. Este tipo de tareas tendrá una duración de 1 hora de gimnasio y 2 horas y 30 minutos en la piscina. Se organizará de la siguiente forma:

\begin{tabular}{|l|l|l|l|l|l|l|l|}
\hline Horario & Lunes & Martes & Miércoles & Jueves & Viernes & Sábado & Domingo \\
\hline $\begin{array}{l}\text { 20:00- } \\
22: 30\end{array}$ & Piscina & & Descanso & Piscina & & Piscina & Descanso \\
\hline $\begin{array}{l}\text { 20:00- } \\
21: 00\end{array}$ & & Gimnasio & Descanso & & Gimnasio & & Descanso \\
\hline
\end{tabular}


La programación de la dieta ira en función de la intensidad (medida según el compendio de actividad física de Ainsworth et al. 2011) y de si el entrenamiento es en piscina o en gimnasio.

Siendo el metabolismo basal del sujeto 1496kcal, el gasto calórico será:

- Intensidad ligera (5,8mets): $4134 \mathrm{kcal}$ aproximadamente con un $70 \%$ en hidratos de carbono, $10 \%$ en grasas y un $20 \%$ en proteínas.

- Intensidad media (8,3mets): $4890 \mathrm{kcal}$ aproximadamente con un $70 \%$ en hidratos de carbono, $10 \%$ en grasas y un $20 \%$ en proteínas.

- Intensidad alta (10 mets): 5000 kcal aproximadamente con $70 \%$ en hidratos de carbono, $10 \%$ en grasas y un $20 \%$ en proteínas.

- Intensidad alta en el gimnasio (6 mets): 4276 kcal aproximadamente con un $60 \%$, en hidratos de carbono, $10 \%$ en grasa y un $30 \%$ en hidratos de carbono.

\subsubsection{Competición.}

Días antes de la competición la ingesta alimenticia debera de ser abundante en carbohidratos de rapida digestión para favorecer la supercomensación y producir asi un aumento de los niveles de glucógeno. En cuanto al plan de entrenamiento se reducira el volumen y la intensidad aunque se haran ejercicios con cargas parecidas a la competición utilizando tiempos de descanso que permitan una recuperacion completa. La organización sera la siguiente.

\begin{tabular}{|l|l|l|l|l|l|l|l|}
\hline Horario & Lunes & Martes & Miércoles & Jueves & Viernes & Sábado & Domingo \\
\hline $\begin{array}{l}\text { 20:00- } \\
\text { 22:30 }\end{array}$ & Piscina & Piscina & Descanso & Piscina & Piscina & Piscina & Descanso \\
\hline
\end{tabular}

Siguiendo estos datos y teniendo en cuenta el metabolismo basal del sujeto la ingesta calorica estara en torno a $3900 \mathrm{kcal}$ con un $80 \%$ de hidratos de carbono, $10 \%$ de proteinas y $5 \%$ de grasa.

La semana antes de la competición el volumen y la intensidad se reduciran. El día de antes se realizará una sesión para entrenar la salida. La organización quedará asi:

\begin{tabular}{|l|l|l|l|l|l|l|l|}
\hline Horario & Lunes & Martes & Miércoles & Jueves & Viernes & Sábado & Domingo \\
\hline $\begin{array}{l}\text { 20:00- } \\
22: 30\end{array}$ & descanso & piscina & Piscina & Piscina & descanso & $\begin{array}{l}\text { Puesta a } \\
\text { punto }\end{array}$ & $\begin{array}{l}\text { Competici } \\
\text { ón }\end{array}$ \\
\hline
\end{tabular}


La ingesta calorica con esta etapa sera de $4000 \mathrm{kcal}$ aproximadamente con el $70 \%$ de hidratos de carbono, 20 de proteinas y 10 de grasas.

Para la elaboracion de la dieta en el día de la competición es muy importante tener en cuenta la hora del día a la que se produzca.

Como la prueba se produce por la tarde, la ingesta de los alimentos se deberá de cumplir 4 horas antes. Según Ramirez (2006), es conveniente evitar la toma de grandes cantidades de alimentos por lo que se deberá de ingerir una dieta hipocalórica rica en hidratos de carbono y pobre en grasas, proteínas y fibras (700-900 kcalorías aproximadamente). Además el deportista deberá de tener una hidratación óptima y tendrá que evitar las comidas muy condimentadas. Intentaremos que los alimentos que tome el deportista sean familiares para el evitando así algún tipo de problema.

Tal y como hemos dicho anteriormente, la prueba a realizar será de 200 metros crol y el horario estipulado es sobre las 17:00 de la tarde.

Según Ainsworth et al. (2011), el consumo total de la prueba será de 11 mets por lo que el gasto calórico diario total será de 3083 kcal.

Una vez que ha terminado la competición la dieta debe de ser rica en hidratos de carbono para reponer todo el glucógeno a nivel muscular y hepático que ha sido agotado.

Esta dieta deberá de estar reforzada con proteínas ya que permitirán restaurar los daños que se hayan podido ocasionar más rápidamente. (Paz-Lasanta, 2004).

Tal y como hace referencia Fernández 2003, la ingesta de hidratos de carbono debe de estar comprendida entre el 55 y el $65 \%$ del total de calorías así como la de proteínas debe de ser entre el 8 y $15 \%$ y la de lípidos entre un $25 \%$. Estos porcentajes variaran atendiendo al periodo de entrenamiento, pre competición o competición

En base a todo esto, el porcentaje conveniente en macronutrientes será de $63 \%$ de hidratos de carbono $15 \%$ de grasas y $22 \%$, siendo el gasto calórico de $3631 \mathrm{kcal}$ aproximadamente.

Debido a que el día después de la competición no se realizara ninguna actividad, realizaremos una dieta con un alto contenido en hidratos de carbono y proteínas siendo el porcentaje de $60 \%$ de HC, 30\% de proteínas y un $10 \%$ de grasas.

\subsubsection{Recuperación.}


Una vez termina la competición la dieta del deportista debe de ser rica en hidratos de carbono para favorecer la rápida reposición de glucógeno tanto en el músculo como en el hígado que han sido agotados durante la prueba. Además de la ingesta de los hidratos, la dieta debe de ser reforzada con proteínas para restaurar los daños que hayan podido presentarse durante la prueba. (Paz-Lasanta, I., 2004). La ingesta de agua también será fundamental para reponerse de la competición siempre y cuando también esté acompañada de sales minerales.

El día de después de la competición realizará un día entero de descanso y los demás días de la semana realizará un entrenamiento suave de descarga y no realizara sesiones de gimnasio. Si la competición se produjo el sábado la organización seria la siguiente.

\begin{tabular}{|l|l|l|l|l|l|l|l|}
\hline Horario & domingo & Lunes & Martes & Miércoles & Jueves & Viernes & Sábado \\
\hline $20: 00-$ & Descanso & $\begin{array}{l}\text { Entrenami } \\
\text { ento en } \\
\text { piscina a } \\
\text { baja } \\
\text { intensidad }\end{array}$ & Descanso & $\begin{array}{l}\text { Entrenami } \\
\text { ento en } \\
\text { piscina de } \\
\text { baja } \\
\text { intensidad }\end{array}$ & Descanso & $\begin{array}{l}\text { Entrenamiento } \\
\text { en piscina de } \\
\text { baja } \\
\text { intensidad }\end{array}$ & \\
& & & & & \\
\hline
\end{tabular}

El gasto calórico será alrededor de 3500 y 4500 kcal aproximadamente.

El porcentaje de macronutrientes oscilara entre el $60 \%$ de hidratos de carbono, el $30 \%$ de proteínas y el $10 \%$ de grasas.

\subsubsection{Lesión.}

En la lesión, la metodología que se va a utilizar será la de una reducción lipídica y de carbohidratos ya que su gasto calórico va a disminuir debido a la inmovilización que tendrá que llevar a cabo para el proceso de recuperación. Con esto mantenemos que su composición corporal no se vea demasiada afectada.

Realizando 10 horas de actividad en reposo 11 horas de actividad muy ligera, 2 horas de actividad ligera y 1 hora de actividad moderada para la realización de la recuperación, el gasto calórico será en torno a 2800 $2900 \mathrm{kcal}$ aproximadamente siendo el porcentaje alrededor del 60\% de hidratos de carbono, $30 \%$ de proteínas y $10 \%$ de grasa.

\subsubsection{Hidratación durante los periodos.}

Según indica Paz Lasanta. (2004) cuando el ejercicio que realizamos es de baja intensidad y es inferior a una hora no será necesario una 
suplementación hídrica debido a que con la metabolización de los alimentos es suficiente para compensar la pérdida.

En cambio cuando el ejercicio pasa de la hora y la intensidad es mediabaja si es necesario una suplementación hídrica. Cuando esto ocurre, se deberá de hidratar al deportista con $500 \mathrm{ml}$ de agua una hora antes de la actividad añadiendo incluso $40-60 \mathrm{gr}$ de hidratos de carbono y 0.5 de cloruro sódico. Durante el entrenamiento es imprescindible una hidratación de $200 \mathrm{ml}$ cada media hora aproximadamente. Después del entrenamiento e incluso de la competición será el deportista el que ingiera las cantidades de agua que el desee siendo $500 \mathrm{ml}$ el mínimo añadiendo 50-60gr de hidratos de carbono para empezar a reponer el desnivel de los hidratos.

Para no llegar a una deshidratación también es necesario que el líquido que ingiere el deportista tenga una concentración de hidratos de carbono del 5 al $8 \%$ cuando aumente más de una hora además de evitar el consumo de cafeína o bebidas carbonatadas y no esperar a que el sujeto no sienta sed o tenga una ligera deshidratación.

\section{RESULTADOS.}

\subsection{Resultados del cuestionario de recuerdo de la dieta de 3 días.}

Según el cuestionario, el deportista abusa mucho de los hidratos de carbono de alto índice glucémico, además de las grasas sobre todo por la tarde y noche. Come muy pocas verduras y la que come suele ser la misma, lechuga y tomate. No suele comer nada de hortalizas ni legumbres.

\subsection{Pautas generales de actuación en la intervención de la dieta.}

El sujeto de estudio no tiene ninguna intolerancia a ningún tipo de alimentos por lo que podrá comer absolutamente de todo aunque según se ha podido ver en el cuestionario de recuerdo y que el mismo lo afirma, no suele consumir mucha verdura más allá del tomate y la lechuga, legumbres o pescado porque no es mucho de su agrado.

La estrategia que voy a seguir es darle una tabla donde aparezca dividida cada comida y los alimentos que deberá de consumir eligiendo él cada día lo que le apetezca más. Esta tabla contendrá también el número de veces que podrá comerlo durante la semana. 
El seguimiento que se va a realizar a través de los datos que nos proporcione la bioimpedancia y según como se encuentre aumentare o disminuiré las cantidades de macronutrientes. También tendré en cuenta su rendimiento en el entrenamiento a la hora de variar las cantidades.

Para saber si el deportista tiene unos niveles de hidratación óptima le diríamos que se observase la orina. Si es de un color amarillo muy claro, casi transparente está llevando una buena hidratación pero si es aspecto es de un amarillo oscuro será todo lo contrario.

\subsection{Dieta según el estadio.}

\subsubsection{Pretemporada.}




\section{A. Entrenamiento en piscina de intensidad baja}

\begin{tabular}{|c|c|c|c|c|c|c|c|c|c|c|c|c|c|c|c|c|c|c|c|c|}
\hline CANT & UND. & $\begin{array}{l}\text { NOMBR } \\
\mathrm{E}\end{array}$ & KCAL & PROT. & $\begin{array}{l}\text { GRAS } \\
\text { AS }\end{array}$ & $\mathrm{HC}$ & Fibra & AGS g & AGM g & AGP $g$ & $\begin{array}{l}\text { Colest } \\
\text { erol mg }\end{array}$ & $\begin{array}{l}\text { Calcio } \\
\mathrm{mg}\end{array}$ & $\begin{array}{l}\text { Hierro } \\
\text { mg }\end{array}$ & $\begin{array}{l}\text { Yodo } \\
\text { mg }\end{array}$ & $\begin{array}{l}\text { Magne } \\
\text { sio mg }\end{array}$ & $\begin{array}{l}\text { Zinc } \\
\mathrm{mg}\end{array}$ & $\begin{array}{l}\text { Selenio } \\
\mathrm{mg}\end{array}$ & $\begin{array}{l}\text { Sodio } \\
\text { mg }\end{array}$ & $\begin{array}{l}\text { Potasio } \\
\text { mg }\end{array}$ & $\begin{array}{l}\text { Fosforo } \\
\text { mg }\end{array}$ \\
\hline \multicolumn{21}{|c|}{ 09:00 - Desayuno } \\
\hline 10 & gr. & $\begin{array}{l}\text { almendra } \\
\text { sin } \\
\text { cascara. }\end{array}$ & 61 & 1,9 & 5,4 & 0,5 & 1,4 & 0,4 & 3,3 & 1,3 & 0 & 25,2 & 0,4 & 0,2 & 27 & 0,3 & 0,4 & 1,4 & 83,5 & 9 \\
\hline 50 & gr. & miel. & 151 & 0,2 & 0 & 37,6 & 0 & 0 & 0 & 0 & 0 & 3 & 0,6 & 0,2 & 0,8 & 0,2 & 2,4 & 1,2 & 22,5 & 3,4 \\
\hline 200 & gr. & $\begin{array}{l}\text { leche de } \\
\text { soja. }\end{array}$ & 110 & 6,4 & 3,7 & 11,5 & 2,6 & 0,4 & 0,6 & 1,6 & 0 & 6 & 1,6 & 0 & 56 & 0,8 & 2,6 & 6 & 382 & 0 \\
\hline 200 & gr. & $\begin{array}{l}\text { zumo de } \\
\text { pomelo. }\end{array}$ & 87,2 & 1,1 & 0,2 & 20,2 & 0,2 & 0 & 0 & 0 & 0 & 18,6 & 1,1 & 2 & 16 & 0,2 & 0,2 & 2,6 & 298 & 0 \\
\hline 5 & gr. & $\begin{array}{l}\text { sal } \\
\text { comun. }\end{array}$ & 0 & 0 & 0 & 0 & 0 & 0 & 0 & 0 & 0 & 1,4 & 0 & 2,2 & 14,5 & 0 & 0 & 1943 & 0 & 0 \\
\hline 6 & gr. & $\begin{array}{l}\text { aceite de } \\
\text { oliva } \\
\text { viraen. }\end{array}$ & 53,9 & 0,1 & 6 & 0 & 0 & 0,9 & 4,3 & 0,6 & 0 & 0 & 0 & 0 & 0 & 0,1 & 0,1 & 0 & 0 & 0 \\
\hline 40 & gr. & tomate. & 8,9 & 0,4 & 0,1 & 1,4 & 0,6 & 0 & 0 & 0 & 0 & 4,2 & 0,3 & 0,9 & 3,3 & 0,1 & 0,4 & 3,6 & 96,8 & 9,6 \\
\hline 70 & gr. & $\begin{array}{l}\text { cereales } \\
\text { con base } \\
\text { de maiz }\end{array}$ & 263,2 & 5,6 & 0,6 & 58,1 & 1,8 & 0,2 & 0,1 & 0,2 & 0 & 7 & 5,5 & 3,5 & 10,5 & 0,1 & 1,8 & 70 & 70 & 0 \\
\hline \multirow[t]{2}{*}{100} & gr. & $\begin{array}{l}\text { pan } \\
\text { integral } \\
\text { tostado. }\end{array}$ & 265 & 10,8 & 2,9 & 44,5 & 8,7 & 0,6 & 0,6 & 0,9 & 0 & 63 & 3,2 & 1 & 89 & 2,1 & 41 & 640 & 270 & 0 \\
\hline & & Total. & 1000 & 26,5 & 18,9 & 173,8 & & & & & & & & & & & & & & \\
\hline \multicolumn{21}{|c|}{ 12:00 - Media mañana } \\
\hline 250 & gr. & $\begin{array}{l}\text { yogur } \\
\text { desnatad } \\
\text { o natural. }\end{array}$ & 112,2 & 10,6 & 0,8 & 15,8 & 0 & 0,3 & 0,4 & 0 & 2,5 & 350 & 0,2 & 13,2 & 34,2 & 1,1 & 2,5 & 142,5 & 467,5 & 50 \\
\hline 80 & gr. & pera. & 39,5 & 0,3 & 0,1 & 8,5 & 1,8 & 0 & 0 & 0 & 0 & 7,7 & 0,2 & 1,7 & 6,7 & 0,2 & 0,5 & 1,7 & 92,8 & 7,9 \\
\hline & & Total. & 151,7 & 10,9 & 0,9 & 24,3 & & & & & & & & & & & & & & \\
\hline \multicolumn{21}{|c|}{ 15:00 - Almuerzo } \\
\hline 200 & gr. & manzana & 108,2 & 0,6 & 0,7 & 22,8 & 4 & 0,1 & 0,3 & 0,2 & 0 & 11 & 1,1 & 2,2 & 11,2 & 0,3 & 2,8 & 2,4 & 240 & 18,2 \\
\hline 250 & gr. & pasta. & 897,5 & 32 & 4 & 177,3 & 12,5 & 0,6 & 0,5 & 1,6 & 0 & 60 & 4,5 & 25 & 120 & 3 & 155,5 & 17,5 & 590 & 0 \\
\hline 100 & gr. & $\begin{array}{l}\text { sal } \\
\text { comun. }\end{array}$ & 0 & 0 & 0 & 0 & 0 & 0 & 0 & 0 & 0 & 29 & 0,2 & 44 & 290 & 0,1 & 0,1 & 38850 & 0 & 0 \\
\hline 80 & gr. & tomate. & 17,7 & 0,7 & 0,2 & 2,8 & 1,1 & 0 & 0 & 0,1 & 0 & 8,5 & 0,6 & 1,8 & 6,6 & 0,1 & 0,8 & 7,2 & 193,6 & 19,2 \\
\hline 70 & gr. & lechuga. & 13,7 & 1 & 0,4 & 1 & 1 & 0,1 & 0 & 0,3 & 0 & 24,3 & 0,7 & 2,1 & 6,1 & 0,2 & 0,7 & 2,1 & 154 & 0 \\
\hline 5 & gr. & vinagre. & 0,2 & 0 & 0 & 0 & 0 & 0 & 0 & 0 & 0 & 0,8 & 0 & 0 & 1,1 & 0 & 0 & 1 & 4,4 & 0 \\
\hline 40 & gr. & $\begin{array}{l}\text { alga agar } \\
\text { cruda. }\end{array}$ & 11,5 & 0,2 & 0 & 2,5 & 0,2 & 0 & 0 & 0 & 0 & 21,6 & 0,7 & 0 & 26,8 & 0,2 & 0,3 & 3,6 & 90,4 & 0 \\
\hline 10 & gr. & $\begin{array}{l}\text { aceite de } \\
\text { oliva } \\
\text { viraen. } \\
\text { Total. }\end{array}$ & 89,9 & 0,1 & 10 & 206,4 & 0 & 1,4 & 7,1 & 1 & 0 & 0 & 0 & 0 & 0 & 0,1 & 0,1 & 0 & 0 & 0 \\
\hline \multicolumn{21}{|c|}{ 18:00 - Pre-entrenamiento } \\
\hline 80 & gr. & $\begin{array}{l}\text { leche de } \\
\text { vaca } \\
\text { semidesn }\end{array}$ & 38,1 & 2,8 & 1,3 & 3,8 & 0 & 0,9 & 0,4 & 0 & 5 & 100 & 0,1 & 6,9 & 9,5 & 0,4 & 1,2 & 37,6 & 124 & 13,6 \\
\hline 30 & gr. & $\begin{array}{l}\text { almendra } \\
\text { sin } \\
\text { cascara. }\end{array}$ & 183 & 5,6 & 16,2 & 1,6 & 4,1 & 1,2 & 9,9 & 3,9 & 0 & 75,6 & 1,2 & 0,6 & 81 & 1 & 1 & 4,2 & 250,5 & 27 \\
\hline 70 & gr. & te. & 154 & 13,7 & 1,4 & 2,1 & 39,1 & 0,3 & 0,2 & 0,6 & 0 & 211,4 & 11,9 & 7,7 & 128,8 & 2,2 & 3,8 & 9,8 & 1148 & 6,6 \\
\hline 120 & gr. & $\begin{array}{l}\text { cereales } \\
\text { de trigo } \\
\text { intearal }\end{array}$ & 417,6 & 10,8 & 2,4 & 82,8 & 10,8 & 0,4 & 0,3 & 1,7 & 0 & 48 & 7,2 & 6 & 144 & 3 & 34,8 & 12 & 720 & 0 \\
\hline & & Total & 792,7 & 32,9 & 21,3 & 90,3 & & & & & & & & & & & & & & \\
\hline \multicolumn{21}{|c|}{ 22:00 - Post-entrenamiento } \\
\hline 175 & gr. & $\begin{array}{l}\text { pechuga } \\
\text { de pavo. }\end{array}$ & 183,8 & 42,2 & 1,7 & 1,8 & 0 & 0,6 & 0,4 & 0,4 & 78,8 & 14 & 1,8 & 3,5 & 35 & 3,2 & 39,2 & 80,5 & 582,8 & 0 \\
\hline 50 & gr. & $\begin{array}{l}\text { pan } \\
\text { integral. }\end{array}$ & 110,5 & 3,5 & 1,4 & 19 & 3,8 & 0,3 & 0,2 & 0,6 & 0 & 27 & 1,4 & 0,5 & 38 & 0,9 & 17,5 & 275 & 115 & 0 \\
\hline 70 & gr. & platano. & 66,5 & 0,7 & 0,2 & 14,6 & 1,8 & 0,1 & 0 & 0,1 & 0 & 5,1 & 0,4 & 1,7 & 25,5 & 0,1 & 1 & 0,7 & 259 & 9,8 \\
\hline 150 & gr. & $\begin{array}{l}\text { zanahori } \\
\text { a. }\end{array}$ & 59,1 & 1,9 & 0,3 & 10,4 & 3,9 & 0,1 & 0 & 0,2 & 0 & 40,9 & 0,7 & 9,8 & 16,9 & 0,4 & 2 & 91,5 & 481,5 & 28,5 \\
\hline 150 & gr. & $\begin{array}{l}\text { calabaci } \\
\mathrm{n} .\end{array}$ & 34,8 & 2,8 & 0,8 & 3 & 2,4 & 0,2 & 0,2 & 0,2 & 0 & 32,3 & 1 & 3 & 19,3 & 0,4 & 1,5 & 1,5 & 345 & 0 \\
\hline 200 & gr. & $\begin{array}{l}\text { patata } \\
\text { nueva. }\end{array}$ & 147,2 & 4,7 & 0,2 & 29,6 & 4,1 & 0,1 & 0 & 0,1 & 0 & 12,8 & 0,9 & 5,2 & 42 & 0,7 & 3 & 5,4 & 836 & 19,4 \\
\hline 70 & gr. & arroz. & 254,8 & 4,7 & 0,6 & 57,1 & 1 & 0,1 & 0,2 & 0,2 & 0 & 9,8 & 0,6 & 9,8 & 21,7 & 1 & 4,9 & 2,7 & 76,3 & 35 \\
\hline & & Total. & 856,7 & 60,5 & 5,2 & 135,5 & & & & & & & & & & & & & & \\
\hline & & Total día & 3940 & 165,4 & 61,6 & 630,3 & 106,9 & 9,3 & 29 & 15,8 & 86,3 & 1218 & 48,1 & 154,7 & 1282 & 22,5 & 322,1 & 42216 & 7993,6 & 257,2 \\
\hline
\end{tabular}




\section{B. Entrenamiento en piscina a intensidad media.}

\begin{tabular}{|c|c|c|c|c|c|c|c|c|c|c|c|c|c|c|c|c|c|c|c|}
\hline $\begin{array}{l}\text { CANT } \\
\text { (gr) }\end{array}$ & $\begin{array}{l}\text { NOMBR } \\
\text { E }\end{array}$ & KCAL & PROT. & $\begin{array}{l}\text { GRAS } \\
\text { AS }\end{array}$ & $\mathrm{HC}$ & Fibra & AGS $\mathrm{g}$ & AGM g & AGP g & $\begin{array}{l}\text { Colest } \\
\text { erol mg }\end{array}$ & $\begin{array}{l}\text { Calcio } \\
\mathrm{mg}\end{array}$ & $\begin{array}{l}\text { Hierro } \\
\mathrm{mg}\end{array}$ & $\begin{array}{l}\text { Yodo } \\
\text { mg }\end{array}$ & $\begin{array}{l}\text { Magne } \\
\text { sio mg }\end{array}$ & $\begin{array}{l}\text { Zinc } \\
\text { mg }\end{array}$ & $\begin{array}{l}\text { Seleni } \\
\text { o mg }\end{array}$ & $\begin{array}{l}\text { Sodio } \\
\text { mg }\end{array}$ & $\begin{array}{l}\text { Potasio } \\
\text { mg }\end{array}$ & $\begin{array}{l}\text { Fosforo } \\
\text { mg }\end{array}$ \\
\hline \multicolumn{20}{|c|}{ 08:00 - Desayuno } \\
\hline 200 & $\begin{array}{l}\text { leche de } \\
\text { vaca } \\
\text { desnatad }\end{array}$ & 74 & 7,8 & 0,4 & 9,8 & $\mathrm{o}$ & 0,2 & 0,1 & $\mathrm{o}$ & 5,2 & 241,8 & 0,2 & 22,2 & 57,2 & 1,1 & 3,2 & 106 & 300 & $\mathrm{o}$ \\
\hline 150 & $\begin{array}{l}\text { zumo de } \\
\text { manzana }\end{array}$ & 72,7 & 0,1 & 0,2 & 17,8 & $\mathrm{o}$ & $\mathrm{o}$ & 0 & 0,1 & $\mathrm{o}$ & 10,4 & 0,4 & 1,5 & 6,3 & 0,2 & 0,2 & 3,3 & 174 & 15 \\
\hline 80 & platano. & 76 & 0,8 & 0,2 & 16,6 & 2 & 0,1 & $\mathrm{o}$ & 0,1 & $\mathrm{o}$ & 5,8 & 0,5 & 1,9 & 29,1 & 0,2 & 1,1 & 0,8 & 296 & 11,2 \\
\hline 40 & $\begin{array}{l}\text { cafe en } \\
\text { polvo } \\
\text { soluble. }\end{array}$ & 90,8 & 5,8 & 0,2 & 16,4 & $\mathrm{o}$ & 0,1 & $\mathrm{o}$ & 0,1 & $\mathrm{o}$ & 64 & 1,8 & 0 & 156 & 0,2 & 5 & 16,4 & 1600 & 160 \\
\hline 80 & $\begin{array}{l}\text { pan } \\
\text { blanco } \\
\text { sin sal. }\end{array}$ & 212 & 6,4 & 0,9 & 43,1 & 2,8 & 0,2 & 0,1 & 0,3 & $\mathrm{o}$ & 16 & 1,4 & 4 & 20,8 & 0,5 & 18,1 & 1,6 & 80 & $\mathrm{o}$ \\
\hline 60 & $\begin{array}{l}\text { pechuga } \\
\text { de pavo }\end{array}$ & 48,6 & 10,7 & 0,3 & 0,8 & & & & & & & & & & & & & & \\
\hline 70 & $\begin{array}{l}\text { cereales } \\
\text { con base } \\
\text { de arroz. }\end{array}$ & 271,6 & 4,9 & 1 & 60,2 & 0,7 & 0,4 & 0,1 & 0,4 & 0 & 7 & 5,5 & 3,5 & 28 & 0,7 & 10,8 & 490 & 98 & $\mathrm{o}$ \\
\hline 50 & castaña. & 95 & 1,3 & 1,1 & 18,2 & 3,4 & 0,2 & 0,3 & 0,3 & 0 & 18,3 & 0,8 & 0 & 17,2 & 1,2 & 0,9 & 5,5 & 250 & $\mathrm{o}$ \\
\hline & Total. & 940,7 & 37,8 & 4,3 & 182,9 & & & & & & & & & & & & & & \\
\hline \multicolumn{20}{|c|}{ 11:00 - Media mañana } \\
\hline 200 & $\begin{array}{l}\text { pera en } \\
\text { almibar. }\end{array}$ & 138,6 & 0,5 & 0,2 & 32,2 & 3 & $\mathrm{o}$ & $\mathrm{o}$ & $\mathrm{o}$ & $\mathrm{o}$ & 14 & 0,8 & 2 & 8 & 0,2 & 0,4 & 12,2 & 130 & 5,8 \\
\hline 250 & $\begin{array}{l}\text { yogur } \\
\text { desnatad } \\
\text { o natural. }\end{array}$ & 112,2 & 10,6 & 0,8 & 15,8 & $\mathrm{o}$ & 0,3 & 0,4 & $\mathrm{o}$ & 2,5 & 350 & 0,2 & 13,2 & 34,2 & 1,1 & 2,5 & 142,5 & 467,5 & 50 \\
\hline 160 & $\begin{array}{l}\text { atun al } \\
\text { natural. }\end{array}$ & 159 & 37,6 & 1 & 0 & 0 & 0,3 & 0,2 & 0,3 & 81,6 & 44,8 & 1,6 & 20,8 & 43,2 & 1,1 & 128,6 & 512 & 368 & 0 \\
\hline 60 & $\begin{array}{l}\text { pan } \\
\text { blanco } \\
\text { sin sal. }\end{array}$ & 159 & 4,8 & 0,7 & 32,3 & 2,1 & 0,1 & 0,1 & 0,2 & $\mathrm{o}$ & 12 & 1 & 3 & 15,6 & 0,4 & 13,6 & 1,2 & 60 & o \\
\hline & Total. & 568,8 & 53,5 & 2,7 & 80,3 & & & & & & & & & & & & & & \\
\hline \multicolumn{20}{|c|}{ 14:00 - Almuerzo } \\
\hline 100 & $\begin{array}{l}\text { pechuga } \\
\text { de pavo. }\end{array}$ & 105 & 24,1 & 1 & 1 & $\mathrm{o}$ & 0,4 & 0,2 & 0,2 & 45 & 8 & 1 & 2 & 20 & 1,8 & 22,4 & 46 & 333 & o \\
\hline 50 & lechuga. & 9,8 & 0,7 & 0,3 & 0,7 & 0,8 & 0,1 & 0 & 0,2 & $\mathrm{o}$ & 17,4 & 0,5 & 1,5 & 4,4 & 0,1 & 0,5 & 1,5 & 110 & 0 \\
\hline 50 & $\begin{array}{l}\text { remolach } \\
\text { a. }\end{array}$ & 23 & 0,8 & 0 & 4,2 & 1,3 & 0 & 0 & 0 & 0 & 8,5 & 0,5 & 0,2 & 10,5 & 0,2 & 0,3 & 29 & 203,5 & 6 \\
\hline 50 & $\begin{array}{l}\text { zanahori } \\
\text { a. }\end{array}$ & 19,7 & 0,6 & 0,1 & 3,4 & 1,3 & 0 & 0 & 0,1 & 0 & 13,6 & 0,2 & 3,3 & 5,6 & 0,1 & 0,6 & 30,5 & 160,5 & 9,5 \\
\hline 20 & $\begin{array}{l}\text { almendra } \\
\text { tostada } \\
\text { sin }\end{array}$ & 124,2 & 4,6 & 10,6 & 1,3 & 2,7 & 0,8 & 6,7 & 2,5 & 0 & 48 & 0,6 & 0,4 & 54 & 0,7 & 0,2 & 2,8 & 158 & o \\
\hline 150 & arroz. & 546 & 10 & 1,4 & 122,4 & 2,1 & 0,3 & 0,3 & 0,5 & o & 21 & 1,2 & 21 & 46,5 & 2,2 & 10,5 & 5,8 & 163,5 & 75 \\
\hline 30 & $\begin{array}{l}\text { tomate } \\
\text { triturado. }\end{array}$ & 11,4 & 0,7 & 0,2 & 1,7 & 0,4 & 0 & 0 & 0,1 & 0 & 18 & 0,3 & 0,7 & 9,6 & 0,1 & 0,2 & 177 & 348 & o \\
\hline 90 & tomate. & 20 & 0,8 & 0,2 & 3,2 & 1,3 & o & 0 & 0,1 & 0 & 9,5 & 0,6 & 2 & 7,5 & 0,1 & 0,9 & 8,1 & 217,8 & 21,6 \\
\hline 150 & $\begin{array}{l}\text { pera en } \\
\text { almibar. }\end{array}$ & 104 & 0,4 & 0,2 & 24,2 & 2,2 & 0 & 0 & $\mathrm{o}$ & 0 & 10,5 & 0,6 & 1,5 & 6 & 0,2 & 0,3 & 9,2 & 97,5 & 4,4 \\
\hline 5 & vinagre. & 0,2 & $\mathrm{o}$ & $\mathrm{o}$ & o & $\mathrm{O}$ & 0 & 0 & $\mathrm{o}$ & 0 & 0,8 & $\mathrm{o}$ & $\mathrm{o}$ & 1,1 & 0 & o & 1 & 4,4 & o \\
\hline 3 & $\begin{array}{l}\text { aceite de } \\
\text { oliva } \\
\text { viraen. }\end{array}$ & 27 & 0 & 3 & o & 0 & 0,4 & 2,1 & 0,3 & o & o & o & 0 & O & 0 & $\mathrm{O}$ & 0 & $\mathrm{O}$ & o \\
\hline 60 & $\begin{array}{l}\text { gamba } \\
\text { roja. }\end{array}$ & 56,5 & 10,8 & 1,1 & 0,9 & 0 & 0,2 & 0,2 & 0,4 & 111 & 69 & 2 & 54 & 41,4 & 0,7 & 14,6 & 183 & 132,6 & o \\
\hline 100 & $\begin{array}{l}\text { garbanzo } \\
\text { en } \\
\text { conserva }\end{array}$ & 120 & 7,2 & 2,9 & 14,1 & 4,1 & 0,3 & 0,7 & 1,3 & 0 & 43 & 2,8 & 1 & 24 & 1,2 & 1 & 220 & 110 & o \\
\hline 70 & $\begin{array}{l}\text { guisante } \\
\text { congelad } \\
\text { o. }\end{array}$ & 51,8 & 4,2 & 0,3 & 6,7 & 2,9 & 0,1 & 0,1 & $\mathrm{O}$ & 0 & 24,5 & 1,1 & 1,4 & 14,7 & 0,5 & 0,6 & 1,4 & 105 & o \\
\hline & Total. & 1274 & 65,8 & 21,4 & 196,2 & & & & & & & & & & & & & & \\
\hline \multicolumn{20}{|c|}{ 17:00 Pre-entrenamiento. } \\
\hline 100 & $\begin{array}{l}\text { haba } \\
\text { seca. }\end{array}$ & 307 & 26,1 & 2,1 & 33,3 & 25 & 0,3 & 0,3 & 1,1 & $\mathrm{o}$ & 100 & 5,5 & 2 & 190 & 3,1 & 8,2 & 11 & 1090 & o \\
\hline 200 & kiwi. & 103,6 & 2 & 1,6 & 18,2 & 4,2 & 0,2 & 0,2 & 0,8 & $\mathrm{o}$ & 68,2 & 0,7 & 0,7 & 29,9 & 0,3 & 1,2 & 8 & 580 & o \\
\hline 110 & $\begin{array}{l}\text { cereales } \\
\text { con base } \\
\text { de maiz }\end{array}$ & 411,4 & 5 & 0,7 & 95,7 & 1,6 & 0,2 & 0,1 & 0,3 & $\mathrm{o}$ & 498,3 & 8,7 & 5,5 & 5,5 & 0,1 & 4,8 & 660 & 66 & c \\
\hline 200 & $\begin{array}{l}\text { leche de } \\
\text { vaca } \\
\text { desnatad }\end{array}$ & 74 & 7,8 & 0,4 & 9,8 & 0 & 0,2 & 0,1 & 0 & 5,2 & 241,8 & 0,2 & 22,2 & 57,2 & 1,1 & 3,2 & 106 & 300 & c \\
\hline \multicolumn{17}{|c|}{ 22:00 Post-entrenamiento } & & & \\
\hline 175 & $\begin{array}{l}\text { pechuga } \\
\text { de pollo. }\end{array}$ & 253,8 & 38,8 & 10,8 & $\mathrm{o}$ & $\mathrm{o}$ & 3,3 & 3,4 & 2,7 & 108,5 & 24,5 & 1,9 & 12,1 & 36,8 & 1,4 & 11,4 & 115,5 & 462 & c \\
\hline 150 & $\begin{array}{l}\text { clara de } \\
\text { huevo. }\end{array}$ & 73,6 & 16,7 & 0,3 & 1 & $\mathrm{O}$ & 0 & $\mathrm{o}$ & 0 & 0 & 16,5 & 0,3 & 10,2 & 18 & 0 & 8,1 & 255 & 231 & c \\
\hline 200 & manzana & 108,2 & 0,6 & 0,7 & 22,8 & 4 & 0,1 & 0,3 & 0,2 & o & 11 & 1,1 & 2,2 & 11,2 & 0,3 & 2,8 & 2,4 & 240 & 18,2 \\
\hline 150 & $\begin{array}{l}\text { gazpach } \\
\text { o en } \\
\text { conserva }\end{array}$ & 51,6 & 0,9 & 4,2 & 2,4 & 0,3 & 0,7 & 2,8 & 0,5 & 0 & 15 & 0,6 & 1,8 & 4,5 & 0,2 & 2,2 & 454,5 & 138 & c \\
\hline 50 & $\begin{array}{l}\text { pan } \\
\text { blanco } \\
\text { sin sal. }\end{array}$ & 132,5 & 4 & 0,6 & 27 & 1,8 & 0,1 & 0 & 0,2 & 0 & 10 & 0,8 & 2,5 & 13 & 0,3 & 11,3 & 1 & 50 & c \\
\hline 150 & $\begin{array}{l}\text { sopa } \\
\text { jardinera } \\
\text { Dara }\end{array}$ & 528 & 16,8 & 8,2 & 92,8 & 7,5 & 3,8 & 3 & 1,2 & o & 36,4 & 3,3 & 24 & 48,4 & 1,7 & 5,3 & 478,8 & 311 & c \\
\hline & Total. & 1148 & 77,8 & 24,8 & 146 & & & & & & & & & & & & & & \\
\hline & & 4827 & 275,8 & 58 & 762,4 & 78,2 & 13,4 & 21,8 & 14,5 & 359 & 2113 & 49,1 & 244,9 & 1087 & 23,6 & 295,5 & 4116 & 9745,3 & 376,7 \\
\hline
\end{tabular}




\section{Entrenamiento en piscina en intensidad alta.}

\begin{tabular}{|c|c|c|c|c|c|c|c|c|c|c|c|c|c|c|c|c|c|c|c|}
\hline $\begin{array}{l}\text { CANT } \\
(\mathrm{gr})\end{array}$ & $\begin{array}{l}\text { NOMBR } \\
E\end{array}$ & KCAL & PROT. & $\begin{array}{l}\text { GRAS } \\
\text { AS }\end{array}$ & $\mathrm{HC}$ & Fibra & AGS g & AGM g & AGP g & $\begin{array}{l}\text { Colest } \\
\text { erol mg }\end{array}$ & $\begin{array}{l}\text { Calcio } \\
\text { mg }\end{array}$ & $\begin{array}{l}\text { Hierro } \\
\text { mg }\end{array}$ & $\begin{array}{l}\text { Yodo } \\
\text { mg }\end{array}$ & $\begin{array}{l}\text { Magne } \\
\text { sio mg }\end{array}$ & $\begin{array}{l}\text { Zinc } \\
\text { mg }\end{array}$ & $\begin{array}{l}\text { Selenio } \\
\text { mg }\end{array}$ & $\begin{array}{l}\text { Sodio } \\
\text { mg }\end{array}$ & $\begin{array}{l}\text { Potasio } \\
\text { mg }\end{array}$ & $\begin{array}{l}\text { Fosforo } \\
\text { mg }\end{array}$ \\
\hline \multicolumn{20}{|c|}{ 08:00 - Desayuno } \\
\hline 200 & $\begin{array}{l}\text { leche de } \\
\text { vaca }\end{array}$ & 74 & 7,8 & 0,4 & 9,8 & o & 0,2 & 0,1 & 0 & 5,2 & 241,8 & 0,2 & 22,2 & 57,2 & 1,1 & 3,2 & 106 & 300 & o \\
\hline 50 & miel. & 151 & 0,2 & $\mathrm{o}$ & 37,6 & 0 & 0 & 0 & o & $\mathrm{o}$ & 3 & 0,6 & 0,2 & 0,8 & 0,2 & 2,4 & 1,2 & 22,5 & 3,4 \\
\hline 150 & $\begin{array}{l}\text { zumo de } \\
\text { naranja. }\end{array}$ & 65,3 & 1 & 0,3 & 14,1 & 1 & $\mathrm{o}$ & 0,1 & 0,1 & $\mathrm{o}$ & 16,2 & 0,2 & 1,5 & 16,3 & 0,2 & 1,5 & 1,5 & 214,5 & 1,4 \\
\hline 40 & $\begin{array}{l}\text { pan } \\
\text { blanco } \\
\text { sin sal. }\end{array}$ & 106 & 3,2 & 0,4 & 21,6 & 1,4 & 0,1 & $\mathrm{o}$ & 0,2 & 0 & 8 & 0,7 & 2 & 10,4 & 0,2 & 9 & 0,8 & 40 & o \\
\hline 80 & $\begin{array}{l}\text { cereales } \\
\text { con base } \\
\text { de maiz. }\end{array}$ & 300,8 & 6,4 & 0,6 & 66,4 & 2 & 0,2 & 0,1 & 0,2 & 0 & 8 & 6,3 & 4 & 12 & 0,2 & 2,1 & 80 & 80 & 0 \\
\hline 50 & $\begin{array}{l}\text { mermela } \\
\text { da de } \\
\text { albaricoa }\end{array}$ & 129,1 & 0,2 & 0,1 & 31,6 & 0,6 & $\mathrm{O}$ & 0,1 & 0 & 0 & 10 & 0,2 & 1,4 & 2 & $\mathrm{o}$ & 1 & 20 & 38,5 & $\mathrm{O}$ \\
\hline 100 & higo. & 65,4 & 1,3 & 0,5 & 12,9 & 2 & 0,1 & 0,1 & 0,2 & $\mathrm{o}$ & 54 & 0,6 & 1,5 & 20 & 0,2 & 1,6 & 1,3 & 248 & 20 \\
\hline \multirow[t]{2}{*}{80} & $\begin{array}{l}\text { yogur } \\
\text { desnatad } \\
\text { o natural. }\end{array}$ & 35,9 & 3,4 & 0,3 & 5 & O & 0,1 & 0,1 & o & 0,8 & 112 & 0,1 & 4,2 & 11 & 0,4 & 0,8 & 45,6 & 149,6 & 16 \\
\hline & Total. & 927,5 & 23,5 & 2,6 & 199 & & & & & & & & & & & & & & \\
\hline \multicolumn{20}{|c|}{ 11:00 - Media mañana } \\
\hline 150 & $\begin{array}{l}\text { albaricoq } \\
\text { ue seco } \\
\text { oreiones. }\end{array}$ & 424,5 & 5,1 & 0,8 & 94 & 11 & $\mathrm{o}$ & 0,1 & 0,1 & $\mathrm{o}$ & 82,5 & 4 & 1,5 & 48 & 0,6 & 3,3 & 15 & 1743 & $\mathrm{o}$ \\
\hline 50 & $\begin{array}{l}\text { barrita de } \\
\text { cereales } \\
\text { con }\end{array}$ & 196 & 4 & 2,5 & 39 & 0,8 & 1 & $\mathrm{O}$ & 0 & 0 & 0 & 5,5 & $\mathrm{o}$ & $\mathrm{o}$ & $\mathrm{o}$ & 0 & 0,2 & 0 & o \\
\hline 125 & $\begin{array}{l}\text { yogur } \\
\text { desnatad } \\
\text { o natural. } \\
\text { Total. }\end{array}$ & 676,6 & 5,3 & 0,4 & 140,9 & $\mathrm{o}$ & 0,1 & 0,2 & 0 & 1,2 & 175 & 0,1 & 6,6 & 17,1 & 0,6 & 1,2 & 71,2 & 233,8 & 25 \\
\hline \multicolumn{20}{|c|}{ 14:00 - Almuerzo } \\
\hline 60 & $\begin{array}{l}\text { almendra } \\
\text { sin } \\
\text { cascara. }\end{array}$ & 366 & 11,2 & 32,5 & 3,2 & 8,1 & 2,5 & 19,9 & 7,7 & o & 151,2 & 2,5 & 1,2 & 162 & 1,9 & 2,1 & 8,4 & 501 & 54 \\
\hline 5 & vinagre. & 0,2 & o & O & o & O & o & o & o & o & 0,8 & O & o & 1,1 & o & o & 1 & 4,4 & $\mathrm{O}$ \\
\hline 5 & $\begin{array}{l}\text { aceite de } \\
\text { oliva } \\
\text { viraen. }\end{array}$ & 45 & 0 & 5 & 0 & O & 0,7 & 3,6 & 0,5 & $\mathrm{o}$ & $\mathrm{O}$ & O & $\mathrm{o}$ & o & $\mathrm{o}$ & 0 & $\mathrm{o}$ & 0 & o \\
\hline 40 & lechuga. & 7,8 & 0,5 & 0,2 & 0,6 & 0,6 & $\mathrm{o}$ & $\mathrm{o}$ & 0,1 & o & 13,9 & 0,4 & 1,2 & 3,5 & 0,1 & 0,4 & 1,2 & 88 & o \\
\hline 85 & tomate. & 18,8 & 0,7 & 0,2 & 3 & 1,2 & $\mathrm{O}$ & o & 0,1 & o & 9 & 0,6 & 1,9 & 7,1 & 0,1 & 0,8 & 7,6 & 205,7 & 20,4 \\
\hline 50 & $\begin{array}{l}\text { atun al } \\
\text { natural. }\end{array}$ & 49,7 & 11,8 & 0,3 & o & o & 0,1 & o & 0,1 & 25,5 & 14 & 0,5 & 6,5 & 13,5 & 0,4 & 40,2 & 160 & 115 & o \\
\hline 300 & $\begin{array}{l}\text { canelone } \\
\text { s de } \\
\text { carne }\end{array}$ & 396 & 18,6 & 16,2 & 40,5 & 6,7 & 5,6 & 4,4 & 3 & 90 & 460,5 & 6,6 & 53,7 & 89,7 & 1,6 & 51,9 & 1618 & 609,6 & o \\
\hline 60 & $\begin{array}{l}\text { remolach } \\
\text { a. }\end{array}$ & 27,7 & 0,9 & 0,1 & 5 & 1,5 & 0 & o & o & O & 10,2 & 0,5 & 0,2 & 12,6 & 0,2 & 0,4 & 34,8 & 244,2 & 7,2 \\
\hline 50 & $\begin{array}{l}\text { pan } \\
\text { blanco } \\
\text { tipo }\end{array}$ & 129 & 4,8 & 0,6 & 25,3 & 1,8 & 0,1 & 0 & 0,2 & o & 11,5 & 0,8 & 3 & 14 & 0,4 & 14 & 285 & 65 & o \\
\hline 200 & pera. & 98,8 & 0,9 & 0,2 & 21,2 & 4,4 & o & o & 0,1 & o & 19,2 & 0,6 & 4,2 & 16,8 & 0,5 & 1,2 & 4,2 & 232 & 19,8 \\
\hline & Total. & 1139 & 49,4 & 55,3 & 98,8 & & & & & & & & & & & & & & \\
\hline \multicolumn{20}{|c|}{ 17:00 - Pre-entrenamiento } \\
\hline 60 & $\begin{array}{l}\text { mermela } \\
\text { da de } \\
\text { frambues }\end{array}$ & 150,3 & 0,3 & 0,2 & 36,5 & 0,7 & 0 & 0,1 & 0 & 0 & 12 & 0,3 & 1,6 & 2,4 & 0 & 1,2 & 4,2 & 33,6 & o \\
\hline 80 & $\begin{array}{l}\text { pan } \\
\text { blanco } \\
\text { sin sal. }\end{array}$ & 212 & 6,4 & 0,9 & 43,1 & 2,8 & 0,2 & 0,1 & 0,3 & o & 16 & 1,4 & 4 & 20,8 & 0,5 & 18,1 & 1,6 & 80 & o \\
\hline 110 & $\begin{array}{l}\text { cereales } \\
\text { con base } \\
\text { de maiz }\end{array}$ & 411,4 & 5 & 0,7 & 95,7 & 1,6 & 0,2 & 0,1 & 0,3 & o & 498,3 & 8,7 & 5,5 & 5,5 & 0,1 & 4,8 & 660 & 66 & $\mathrm{O}$ \\
\hline 200 & $\begin{array}{l}\text { leche de } \\
\text { vaca } \\
\text { desnatad }\end{array}$ & 74 & 7,8 & 0,4 & 9,8 & o & 0,2 & 0,1 & o & 5,2 & 241,8 & 0,2 & 22,2 & 57,2 & 1,1 & 3,2 & 106 & 300 & o \\
\hline 100 & $\begin{array}{l}\text { haba } \\
\text { seca. }\end{array}$ & 307 & 26,1 & 2,1 & 33,3 & 25 & 0,3 & 0,3 & 1,1 & o & 100 & 5,5 & 2 & 190 & 3,1 & 8,2 & 11 & 1090 & o \\
\hline 200 & $\begin{array}{l}\text { melocoto } \\
\mathrm{n} \text { en } \\
\text { almibar. }\end{array}$ & 117,2 & 0,8 & 0,1 & 28,4 & o & 0 & O & o & o & 7 & 0,6 & 3 & 10,4 & 0,1 & 0,6 & 8 & 206 & 15 \\
\hline & Total. & 1272 & 46,4 & 4,4 & 246,8 & & & & & & & & & & & & & & \\
\hline \multicolumn{20}{|c|}{ 22:00 - Post-entrenamiento } \\
\hline 150 & $\begin{array}{l}\text { calabaci } \\
\text { n. }\end{array}$ & 34,8 & 2,8 & 0,8 & 3 & 2,4 & 0,2 & 0,2 & 0,2 & o & 32,3 & 1 & 3 & 19,3 & 0,4 & 1,5 & 1,5 & 345 & O \\
\hline 175 & $\begin{array}{l}\text { pechuga } \\
\text { de pavo. }\end{array}$ & 183,8 & 42,2 & 1,7 & 1,8 & o & 0,6 & 0,4 & 0,4 & 78,8 & 14 & 1,8 & 3,5 & 35 & 3,2 & 39,2 & 80,5 & 582,8 & o \\
\hline 150 & $\begin{array}{l}\text { pera en } \\
\text { almibar. }\end{array}$ & 104 & 0,4 & 0,2 & 24,2 & 2,2 & $\mathrm{O}$ & $\mathrm{O}$ & o & 0 & 10,5 & 0,6 & 1,5 & 6 & 0,2 & 0,3 & 9,2 & 97,5 & 4,4 \\
\hline 100 & arroz. & 364 & 6,7 & 0,9 & 81,6 & 1,4 & 0,2 & 0,2 & 0,3 & o & 14 & 0,8 & 14 & 31 & 1,5 & 7 & 3,9 & 109 & 50 \\
\hline 50 & $\begin{array}{l}\text { pan } \\
\text { integral. }\end{array}$ & 110,5 & 3,5 & 1,4 & 19 & 3,8 & 0,3 & 0,2 & 0,6 & 0 & 27 & 1,4 & 0,5 & 38 & 0,9 & 17,5 & 275 & 115 & o \\
\hline 130 & $\begin{array}{l}\text { tomate } \\
\text { triturado. }\end{array}$ & 49,5 & 3 & 0,6 & 7,2 & 1,6 & 0,1 & 0,1 & 0,3 & 0 & 78 & 1,3 & 2,9 & 41,6 & 0,4 & 0,8 & 767 & 1508 & o \\
\hline 125 & $\begin{array}{l}\text { zanahori } \\
\text { a. }\end{array}$ & 49,2 & 1,6 & 0,2 & 8,6 & 3,3 & 0 & 0 & 0,2 & 0 & 34 & 0,6 & 8,2 & 14 & 0,4 & 1,6 & 76,2 & 401,2 & 23,8 \\
\hline 150 & $\begin{array}{l}\text { patata } \\
\text { nueva. }\end{array}$ & 110,4 & 3,5 & 0,2 & 22,2 & 3,1 & 0 & o & 0,1 & o & 9,6 & 0,6 & 3,9 & 31,5 & 0,5 & 2,2 & 4,1 & 627 & 14,6 \\
\hline & Total. & 1006 & 63,7 & 6 & 167,6 & & & & & & & & & & & & & & \\
\hline & Total día & 5021 & 197,4 & 72 & 853,1 & 91 & 13,1 & 30,6 & 16,4 & 06,7 & 2495 & 55,8 & 192,8 & 017,8 & 21,3 & 243,3 & 4471 & 10696 & 275 \\
\hline
\end{tabular}




\section{Entrenamiento en el gimnasio.}

\begin{tabular}{|c|c|c|c|c|c|c|c|c|c|c|c|c|c|c|c|c|c|c|c|c|}
\hline CANT & UND. & $\begin{array}{l}\text { NOMBR } \\
\text { E }\end{array}$ & KCAL & PROT. & $\begin{array}{l}\text { GRAS } \\
\text { AS }\end{array}$ & $\mathrm{HC}$ & Fibra & AGS g & AGM g & AGP $g$ & $\begin{array}{l}\text { Colest } \\
\text { erol mg }\end{array}$ & $\begin{array}{l}\text { Calcio } \\
\mathrm{mg}\end{array}$ & $\begin{array}{l}\text { Hierro } \\
\mathrm{mg}\end{array}$ & $\begin{array}{l}\text { Yodo } \\
\text { mg }\end{array}$ & $\begin{array}{l}\text { Magne } \\
\text { sio mg }\end{array}$ & $\begin{array}{l}\text { Zinc } \\
\mathrm{mg}\end{array}$ & $\begin{array}{l}\text { Selenio } \\
\mathrm{mg}\end{array}$ & $\begin{array}{l}\text { Sodio } \\
\mathrm{mg}\end{array}$ & $\begin{array}{l}\text { Potasio } \\
\mathrm{mg}\end{array}$ & $\begin{array}{l}\text { Fosforo } \\
\mathrm{mg}\end{array}$ \\
\hline \multicolumn{21}{|c|}{ 08:00 - Desayuno } \\
\hline 80 & gr. & $\begin{array}{l}\text { yogur } \\
\text { desnatad } \\
\text { o natural. }\end{array}$ & 35,9 & 3,4 & 0,3 & 5 & 0 & 0,1 & 0,1 & 0 & 0,8 & 112 & 0,1 & 4,2 & 11 & 0,4 & 0,8 & 45,6 & 149,6 & 16 \\
\hline 200 & gr. & $\begin{array}{l}\text { leche de } \\
\text { vaca } \\
\text { desnatad }\end{array}$ & 74 & 7,8 & 0,4 & 9,8 & 0 & 0,2 & 0,1 & 0 & 5,2 & 241,8 & 0,2 & 22,2 & 57,2 & 1,1 & 3,2 & 106 & 300 & 0 \\
\hline 50 & gr. & miel. & 151 & 0,2 & 0 & 37,6 & 0 & 0 & 0 & 0 & 0 & 3 & 0,6 & 0,2 & 0,8 & 0,2 & 2,4 & 1,2 & 22,5 & 3,4 \\
\hline 150 & gr. & $\begin{array}{l}\text { zumo de } \\
\text { naranja. }\end{array}$ & 65,3 & 1 & 0,3 & 14,1 & 1 & 0 & 0,1 & 0,1 & 0 & 16,2 & 0,2 & 1,5 & 16,3 & 0,2 & 1,5 & 1,5 & 214,5 & 1,4 \\
\hline 40 & gr. & $\begin{array}{l}\text { pan } \\
\text { blanco } \\
\text { sin sal. }\end{array}$ & 106 & 3,2 & 0,4 & 21,6 & 1,4 & 0,1 & 0 & 0,2 & 0 & 8 & 0,7 & 2 & 10,4 & 0,2 & 9 & 0,8 & 40 & 0 \\
\hline 50 & gr. & $\begin{array}{l}\text { mermela } \\
\text { da de } \\
\text { fresa }\end{array}$ & 16,5 & 0,4 & 0 & 3,2 & 1,2 & 0 & 0 & 0 & 0 & 10,3 & 0,3 & 1,4 & 5,3 & 0 & 1 & 23,5 & 61,5 & 0 \\
\hline \multirow[t]{2}{*}{60} & gr. & $\begin{array}{l}\text { cereales } \\
\text { con base } \\
\text { de maiz. }\end{array}$ & 225,6 & 4,8 & 0,5 & 49,8 & 1,5 & 0,1 & 0,1 & 0,2 & 0 & 6 & 4,7 & 3 & 9 & 0,1 & 1,6 & 60 & 60 & 0 \\
\hline & & Total. & 674,3 & 20,8 & 1,9 & 141,1 & & & & & & & & & & & & & & \\
\hline \multicolumn{21}{|c|}{ 11:00 - Media mañana } \\
\hline 125 & gr. & $\begin{array}{l}\text { yogur } \\
\text { desnatad } \\
\text { o natural }\end{array}$ & 56,1 & 5,3 & 0,4 & 7,9 & 0 & 0,1 & 0,2 & 0 & 1,2 & 175 & 0,1 & 6,6 & 17,1 & 0,6 & 1,2 & 71,2 & 233,8 & 25 \\
\hline 150 & gr. & $\begin{array}{l}\text { albaricoq } \\
\text { ue seco } \\
\text { oreiones. }\end{array}$ & 424,5 & 5,1 & 0,8 & 94 & 11 & 0 & 0,1 & 0,1 & 0 & 82,5 & 4 & 1,5 & 48 & 0,6 & 3,3 & 15 & 1743 & 0 \\
\hline & & Total. & 480,6 & 10,4 & 1,2 & 101,9 & & & & & & & & & & & & & & \\
\hline \multicolumn{21}{|c|}{ 14:00 - Almuerzo } \\
\hline 5 & gr. & vinagre. & 0,2 & 0 & 0 & 0 & 0 & 0 & 0 & 0 & 0 & 0,8 & 0 & 0 & 1,1 & 0 & 0 & 1 & 4,4 & 0 \\
\hline 5 & gr. & $\begin{array}{l}\text { aceite de } \\
\text { oliva } \\
\text { viraen. }\end{array}$ & 45 & 0 & 5 & 0 & 0 & 0,7 & 3,6 & 0,5 & 0 & 0 & 0 & 0 & 0 & 0 & 0 & 0 & 0 & 0 \\
\hline 40 & gr. & lechuga. & 7,8 & 0,5 & 0,2 & 0,6 & 0,6 & 0 & 0 & 0,1 & 0 & 13,9 & 0,4 & 1,2 & 3,5 & 0,1 & 0,4 & 1,2 & 88 & 0 \\
\hline 85 & gr. & tomate. & 18,8 & 0,7 & 0,2 & 3 & 1,2 & 0 & 0 & 0,1 & 0 & 9 & 0,6 & 1,9 & 7,1 & 0,1 & 0,8 & 7,6 & 205,7 & 20,4 \\
\hline 50 & gr. & $\begin{array}{l}\text { atun al } \\
\text { natural. }\end{array}$ & 49,7 & 11,8 & 0,3 & 0 & 0 & 0,1 & 0 & 0,1 & 25,5 & 14 & 0,5 & 6,5 & 13,5 & 0,4 & 40,2 & 160 & 115 & 0 \\
\hline 100 & gr. & pasta. & 359 & 12,8 & 1,6 & 70,9 & 5 & 0,2 & 0,2 & 0,6 & 0 & 24 & 1,8 & 10 & 48 & 1,2 & 62,2 & 7 & 236 & 0 \\
\hline 200 & gr. & pera. & 98,8 & 0,9 & 0,2 & 21,2 & 4,4 & 0 & 0 & 0,1 & 0 & 19,2 & 0,6 & 4,2 & 16,8 & 0,5 & 1,2 & 4,2 & 232 & 19,8 \\
\hline 30 & gr. & $\begin{array}{l}\text { tomate } \\
\text { triturado. }\end{array}$ & 11,4 & 0,7 & 0,2 & 1,7 & 0,4 & 0 & 0 & 0,1 & 0 & 18 & 0,3 & 0,7 & 9,6 & 0,1 & 0,2 & 177 & 348 & 0 \\
\hline 50 & gr. & $\begin{array}{l}\text { pan } \\
\text { blanco } \\
\text { tipo }\end{array}$ & 129 & 4,8 & 0,6 & 25,3 & 1,8 & 0,1 & 0 & 0,2 & 0 & 11,5 & 0,8 & 3 & 14 & 0,4 & 14 & 285 & 65 & 0 \\
\hline 60 & gr. & $\begin{array}{l}\text { almendra } \\
\text { sin } \\
\text { cascara. }\end{array}$ & 366 & 11,2 & 32,5 & 3,2 & 8,1 & 2,5 & 19,9 & 7,7 & 0 & 151,2 & 2,5 & 1,2 & 162 & 1,9 & 2,1 & 8,4 & 501 & 54 \\
\hline \multirow[t]{2}{*}{60} & gr. & $\begin{array}{l}\text { remolach } \\
\text { a. }\end{array}$ & 27,7 & 0,9 & 0,1 & 5 & 1,5 & 0 & 0 & 0 & 0 & 10,2 & 0,5 & 0,2 & 12,6 & 0,2 & 0,4 & 34,8 & 244,2 & 7,2 \\
\hline & & Total. & 1113 & 44,3 & 40,9 & 130,9 & & & & & & & & & & & & & & \\
\hline \multicolumn{21}{|c|}{ 17:00 - Merienda } \\
\hline 125 & gr. & $\begin{array}{l}\text { yogur } \\
\text { desnatad } \\
\text { o natural. }\end{array}$ & 56,1 & 5,3 & 0,4 & 7,9 & 0 & 0,1 & 0,2 & 0 & 1,2 & 175 & 0,1 & 6,6 & 17,1 & 0,6 & 1,2 & 71,2 & 233,8 & 25 \\
\hline 200 & gr. & manzana & 108,2 & 0,6 & 0,7 & 22,8 & 4 & 0,1 & 0,3 & 0,2 & 0 & 11 & 1,1 & 2,2 & 11,2 & 0,3 & 2,8 & 2,4 & 240 & 18,2 \\
\hline \multirow[t]{2}{*}{50} & gr. & $\begin{array}{l}\text { barrita de } \\
\text { cereales } \\
\text { con } \\
\text { Total. }\end{array}$ & 196 & 9,9 & 2,5 & 39 & 0,8 & 1 & 0 & 0 & 0 & 0 & 5,5 & 0 & 0 & 0 & 0 & 0,2 & 0 & 0 \\
\hline & & Total. & 360,3 & 9,9 & 3,6 & 69,7 & & & & & & & & & & & & & & \\
\hline \multicolumn{21}{|c|}{ 21:00 - Cena } \\
\hline 125 & gr. & $\begin{array}{l}\text { zanahori } \\
\text { a. }\end{array}$ & 49,2 & 1,6 & 0,2 & 8,6 & 3,3 & 0 & 0 & 0,2 & 0 & 34 & 0,6 & 8,2 & 14 & 0,4 & 1,6 & 76,2 & 401,2 & 23,8 \\
\hline 150 & gr. & $\begin{array}{l}\text { calabaci } \\
\text { n. }\end{array}$ & 34,8 & 2,8 & 0,8 & 3 & 2,4 & 0,2 & 0,2 & 0,2 & 0 & 32,3 & 1 & 3 & 19,3 & 0,4 & 1,5 & 1,5 & 345 & 0 \\
\hline 130 & gr. & $\begin{array}{l}\text { tomate } \\
\text { triturado. }\end{array}$ & 49,5 & 3 & 0,6 & 7,2 & 1,6 & 0,1 & 0,1 & 0,3 & 0 & 78 & 1,3 & 2,9 & 41,6 & 0,4 & 0,8 & 767 & 1508 & 0 \\
\hline 150 & gr. & $\begin{array}{l}\text { patata } \\
\text { nueva. }\end{array}$ & 110,4 & 3,5 & 0,2 & 22,2 & 3,1 & 0 & 0 & 0,1 & 0 & 9,6 & 0,6 & 3,9 & 31,5 & 0,5 & 2,2 & 4,1 & 627 & 14,6 \\
\hline 50 & gr. & $\begin{array}{l}\text { pan } \\
\text { integral. }\end{array}$ & 110,5 & 3,5 & 1,4 & 19 & 3,8 & 0,3 & 0,2 & 0,6 & 0 & 27 & 1,4 & 0,5 & 38 & 0,9 & 17,5 & 275 & 115 & 0 \\
\hline 150 & gr. & $\begin{array}{l}\text { pechuga } \\
\text { de pollo. }\end{array}$ & 217,5 & 33,3 & 9,3 & 0 & 0 & 2,9 & 2,9 & 2,3 & 93 & 21 & 1,6 & 10,4 & 31,5 & 1,2 & 9,8 & 99 & 396 & 0 \\
\hline 100 & gr. & kiwi. & 51,8 & 1 & 0,8 & 9,1 & 2,1 & 0,1 & 0,1 & 0,4 & 0 & 34,1 & 0,4 & 0,3 & 14,9 & 0,2 & 0,6 & 4 & 290 & 0 \\
\hline \multirow[t]{3}{*}{100} & gr. & arroz. & 364 & 6,7 & 0,9 & 81,6 & 1,4 & 0,2 & 0,2 & 0,3 & 0 & 14 & 0,8 & 14 & 31 & 1,5 & 7 & 3,9 & 109 & 50 \\
\hline & & Total. & 987,7 & 55,4 & 14,2 & 150,7 & & & & & & & & & & & & & & \\
\hline & & Total. & 3616 & 140,8 & 61,8 & 594,3 & 61,6 & 9,2 & 28,6 & 14,7 & 126,9 & 1363 & 33,3 & 123,5 & 713,4 & 14,7 & 190,5 & 2316 & 9129,2 & 278,8 \\
\hline
\end{tabular}




\subsubsection{Competición}

\section{Dos días antes de la competición}

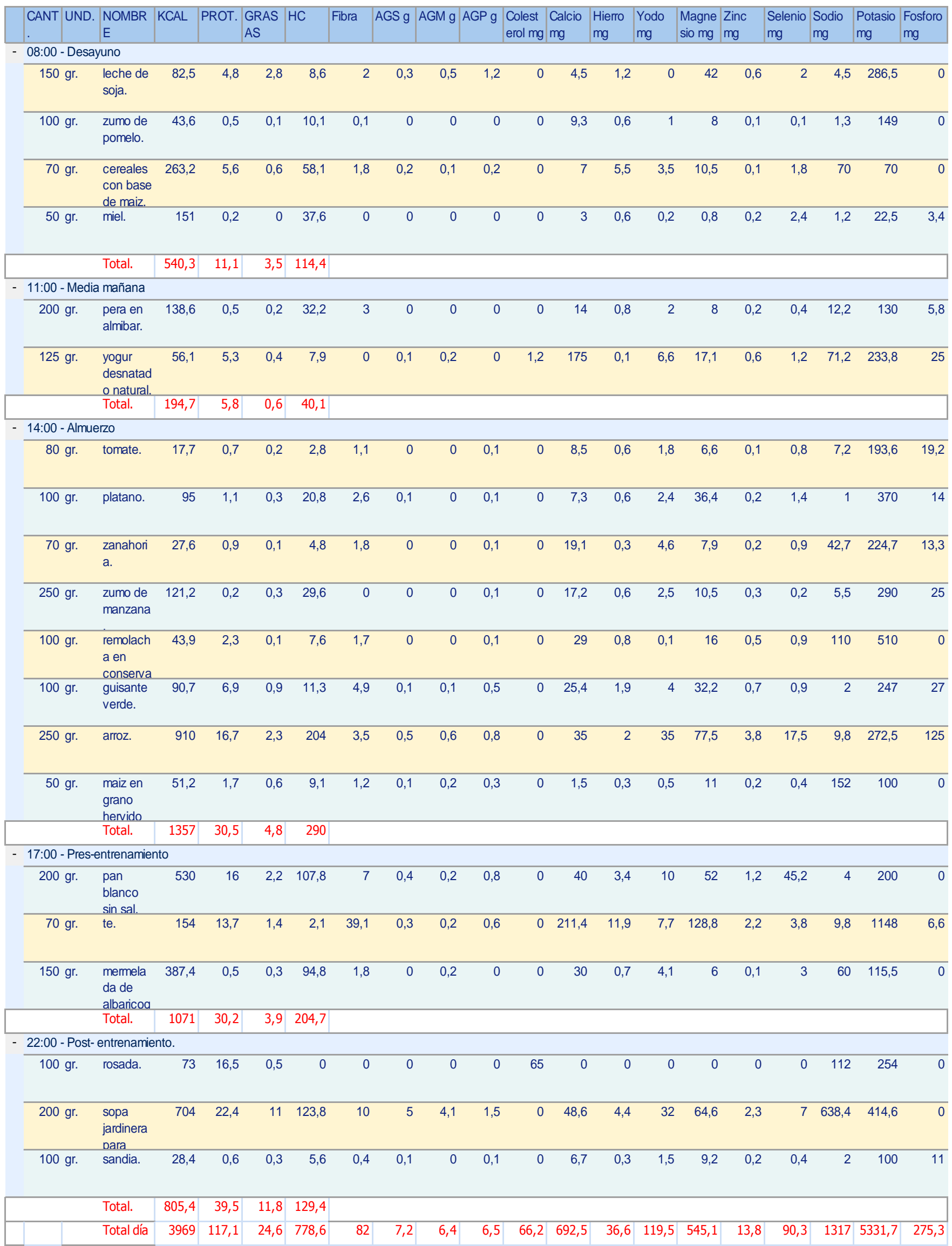




\section{B. Un día antes de la competición.}

\begin{tabular}{|c|c|c|c|c|c|c|c|c|c|c|c|c|c|c|c|c|c|c|c|c|}
\hline CANT & UND. & $\begin{array}{l}\text { NOMBR } \\
\text { E }\end{array}$ & KCAL & PROT. & $\begin{array}{l}\text { GRAS } \\
\text { AS }\end{array}$ & $\mathrm{HC}$ & Fibra & AGS $\mathrm{g}$ & AGM g & AGP $g$ & $\begin{array}{l}\text { Colest } \\
\text { erol mg }\end{array}$ & $\begin{array}{l}\text { Calcio } \\
\text { mg }\end{array}$ & $\begin{array}{l}\text { Hierro } \\
\text { mg }\end{array}$ & $\begin{array}{l}\text { Yodo } \\
\text { mg }\end{array}$ & $\begin{array}{l}\text { Magne } \\
\text { sio mg }\end{array}$ & $\begin{array}{l}\text { Zinc } \\
\text { mg }\end{array}$ & $\begin{array}{l}\text { Selenio } \\
\text { mg }\end{array}$ & $\begin{array}{l}\text { Sodio } \\
\text { mg }\end{array}$ & $\begin{array}{l}\text { Potasio } \\
\text { mg }\end{array}$ & $\begin{array}{l}\text { Fosforo } \\
\text { mg }\end{array}$ \\
\hline \multicolumn{21}{|c|}{ 8:00 - Desayuno } \\
\hline 50 & gr. & miel. & 151 & 0,2 & 0 & 37,6 & 0 & o & 0 & 0 & 0 & 3 & 0,6 & 0,2 & 0,8 & 0,2 & 2,4 & 1,2 & 22,5 & 3,4 \\
\hline 40 & gr. & $\begin{array}{l}\text { pan } \\
\text { blanco } \\
\text { sin sal. }\end{array}$ & 106 & 3,2 & 0,4 & 21,6 & 1,4 & 0,1 & 0 & 0,2 & O & 8 & 0,7 & 2 & 10,4 & 0,2 & 9 & 0,8 & 40 & 0 \\
\hline 50 & gr. & $\begin{array}{l}\text { mermela } \\
\text { da de } \\
\text { fresa }\end{array}$ & 16,5 & 0,4 & 0 & 3,2 & 1,2 & $\mathrm{o}$ & 0 & 0 & 0 & 10,3 & 0,3 & 1,4 & 5,3 & 0 & 1 & 23,5 & 61,5 & o \\
\hline 60 & gr. & $\begin{array}{l}\text { cereales } \\
\text { con base } \\
\text { de maiz. }\end{array}$ & 225,6 & 4,8 & 0,5 & 49,8 & 1,5 & 0,1 & 0,1 & 0,2 & 0 & 6 & 4,7 & 3 & 9 & 0,1 & 1,6 & 60 & 60 & 0 \\
\hline 150 & gr. & $\begin{array}{l}\text { ciruela } \\
\text { seca. }\end{array}$ & 328 & 3,3 & 0,8 & 63,6 & 26,7 & 0,1 & 0,5 & 0,2 & 0 & 61,5 & 3,4 & 1,5 & 40,5 & 0,6 & 4,1 & 12 & 1236 & 0 \\
\hline \multirow[t]{2}{*}{200} & gr. & $\begin{array}{l}\text { leche de } \\
\text { vaca }\end{array}$ & 74 & 7,8 & 0,4 & 9,8 & 0 & 0,2 & 0,1 & 0 & 5,2 & 241,8 & 0,2 & 22,2 & 57,2 & 1,1 & 3,2 & 106 & 300 & 0 \\
\hline & & $\begin{array}{l}\text { desnatad } \\
\text { Total. }\end{array}$ & 901,1 & 19,7 & 2,1 & 185,6 & & & & & & & & & & & & & & \\
\hline \multicolumn{21}{|c|}{ 11:00 Media Mañana } \\
\hline 80 & gr. & $\begin{array}{l}\text { albaricoq } \\
\text { ue seco } \\
\text { oreiones. }\end{array}$ & 226,4 & 2,7 & 0,4 & 50,1 & 5,8 & 0 & 0,1 & 0,1 & 0 & 44 & 2,1 & 0,8 & 25,6 & 0,3 & 1,8 & 8 & 929,6 & 0 \\
\hline 50 & gr. & $\begin{array}{l}\text { barrita de } \\
\text { cereales } \\
\text { con }\end{array}$ & 196 & 4 & 2,5 & 39 & 0,8 & 1 & 0 & 0 & 0 & 0 & 5,5 & 0 & 0 & 0 & 0 & 0,2 & 0 & 0 \\
\hline \multirow[t]{2}{*}{125} & gr. & $\begin{array}{l}\text { yogur } \\
\text { desnatad } \\
\text { o natural }\end{array}$ & 56,1 & 5,3 & 0,4 & 7,9 & 0 & 0,1 & 0,2 & 0 & 1,2 & 175 & 0,1 & 6,6 & 17,1 & 0,6 & 1,2 & 71,2 & 233,8 & 25 \\
\hline & & $\begin{array}{l}\text { Total. } \\
\text { Total }\end{array}$ & 478,5 & 12 & 3,3 & 97 & & & & & & & & & & & & & & \\
\hline \multicolumn{21}{|c|}{ 14:00 - Almuerzo } \\
\hline 60 & gr. & $\begin{array}{l}\text { remolach } \\
\text { a. }\end{array}$ & 27,7 & 0,9 & 0,1 & 5 & 1,5 & 0 & 0 & 0 & 0 & 10,2 & 0,5 & 0,2 & 12,6 & 0,2 & 0,4 & 34,8 & 244,2 & 7,2 \\
\hline 5 & gr. & $\begin{array}{l}\text { aceite de } \\
\text { oliva } \\
\text { viraen. }\end{array}$ & 45 & 0 & 5 & 0 & 0 & 0,7 & 3,6 & 0,5 & 0 & 0 & 0 & 0 & 0 & 0 & 0 & 0 & 0 & 0 \\
\hline 40 & gr. & lechuga. & 7,8 & 0,5 & 0,2 & 0,6 & 0,6 & o & 0 & 0,1 & o & 13,9 & 0,4 & 1,2 & 3,5 & 0,1 & 0,4 & 1,2 & 88 & 0 \\
\hline 85 & gr. & tomate. & 18,8 & 0,7 & 0,2 & 3 & 1,2 & o & 0 & 0,1 & 0 & 9 & 0,6 & 1,9 & 7,1 & 0,1 & 0,8 & 7,6 & 205,7 & 20,4 \\
\hline 50 & gr. & $\begin{array}{l}\text { atun al } \\
\text { natural. }\end{array}$ & 49,7 & 11,8 & 0,3 & O & 0 & 0,1 & 0 & 0,1 & 25,5 & 14 & 0,5 & 6,5 & 13,5 & 0,4 & 40,2 & 160 & 115 & 0 \\
\hline 200 & gr. & pera. & 98,8 & 0,9 & 0,2 & 21,2 & 4,4 & 0 & 0 & 0,1 & o & 19,2 & 0,6 & 4,2 & 16,8 & 0,5 & 1,2 & 4,2 & 232 & 19,8 \\
\hline 5 & gr. & vinagre. & 0,2 & 0 & 0 & 0 & 0 & o & 0 & 0 & $\mathrm{O}$ & 0,8 & O & 0 & 1,1 & 0 & 0 & 1 & 4,4 & 0 \\
\hline 85 & gr. & pepino. & 11,3 & 0,5 & 0,2 & 1,6 & 0,6 & 0,1 & 0 & 0,1 & 0 & 15,7 & 0,2 & 0,3 & 6,2 & 0,1 & 0,7 & 2,6 & 119 & 9,4 \\
\hline 250 & gr. & $\begin{array}{l}\text { pisto de } \\
\text { verduras } \\
\text { congelad }\end{array}$ & 141,5 & 7,2 & 0,4 & 21,9 & 11 & 0,1 & 0 & 0,2 & O & 62,5 & 2 & 6,3 & 55 & 1,2 & 0,8 & 677,5 & 422,5 & $\mathrm{O}$ \\
\hline 200 & gr. & $\begin{array}{l}\text { solomillo } \\
\text { de } \\
\text { termera. }\end{array}$ & 206 & 40,4 & 5 & 2 & 0 & 2,2 & 1,8 & 0,6 & 134 & 18,4 & 5,2 & 9,8 & 39,2 & 6,2 & 17,4 & 110 & 712 & 0 \\
\hline 150 & gr. & $\begin{array}{l}\text { patata } \\
\text { nueva. }\end{array}$ & 110,4 & 3,5 & 0,2 & 22,2 & 3,1 & 0 & 0 & 0,1 & 0 & 9,6 & 0,6 & 3,9 & 31,5 & 0,5 & 2,2 & 4,1 & 627 & 14,6 \\
\hline 50 & gr. & $\begin{array}{l}\text { pan } \\
\text { blanco } \\
\text { tipo }\end{array}$ & 129 & 4,8 & 0,6 & 25,3 & 1,8 & 0,1 & 0 & 0,2 & 0 & 11,5 & 0,8 & 3 & 14 & 0,4 & 14 & 285 & 65 & 0 \\
\hline \multirow[t]{2}{*}{30} & gr. & $\begin{array}{l}\text { tomate } \\
\text { triturado. }\end{array}$ & 11,4 & 0,7 & 0,2 & 1,7 & 0,4 & 0 & 0 & 0,1 & 0 & 18 & 0,3 & 0,7 & 9,6 & 0,1 & 0,2 & 177 & 348 & 0 \\
\hline & & Total. & 857,6 & 71,9 & 12,6 & 104,5 & & & & & & & & & & & & & & \\
\hline \multicolumn{21}{|c|}{ 17:00 Pre-entrenamiento } \\
\hline 80 & gr. & $\begin{array}{l}\text { pan } \\
\text { blanco } \\
\text { sin sal. }\end{array}$ & 212 & 6,4 & 0,9 & 43,1 & 2,8 & 0,2 & 0,1 & 0,3 & 0 & 16 & 1,4 & 4 & 20,8 & 0,5 & 18,1 & 1,6 & 80 & 0 \\
\hline 200 & gr. & $\begin{array}{l}\text { pera en } \\
\text { almibar. }\end{array}$ & 138,6 & 0,5 & 0,2 & 32,2 & 3 & o & 0 & 0 & 0 & 14 & 0,8 & 2 & 8 & 0,2 & 0,4 & 12,2 & 130 & 5,8 \\
\hline 50 & gr. & $\begin{array}{l}\text { haba } \\
\text { seca. }\end{array}$ & 153,5 & 13 & 1 & 16,6 & 12,5 & 0,2 & 0,2 & 0,6 & 0 & 50 & 2,8 & 1 & 95 & 1,6 & 4,1 & 5,5 & 545 & 0 \\
\hline 110 & gr. & $\begin{array}{l}\text { cereales } \\
\text { con base } \\
\text { de maiz }\end{array}$ & 411,4 & 5 & 0,7 & 95,7 & 1,6 & 0,2 & 0,1 & 0,3 & 0 & 498,3 & 8,7 & 5,5 & 5,5 & 0,1 & 4,8 & 660 & 66 & 0 \\
\hline 60 & gr. & $\begin{array}{l}\text { mermela } \\
\text { da de } \\
\text { frambues }\end{array}$ & 150,3 & 0,3 & 0,2 & 36,5 & 0,7 & $\mathrm{o}$ & 0,1 & $\mathrm{o}$ & 0 & 12 & 0,3 & 1,6 & 2,4 & 0 & 1,2 & 4,2 & 33,6 & 0 \\
\hline \multirow[t]{2}{*}{200} & gr. & $\begin{array}{l}\text { leche de } \\
\text { vaca } \\
\text { desnatad }\end{array}$ & 74 & 7,8 & 0,4 & 9,8 & 0 & 0,2 & 0,1 & 0 & 5,2 & 241,8 & 0,2 & 22,2 & 57,2 & 1,1 & 3,2 & 106 & 300 & 0 \\
\hline & & $\begin{array}{l}\text { Total. } \\
\text { Total }\end{array}$ & 1140 & 33 & 3,4 & 233,9 & & & & & & & & & & & & & & \\
\hline \multicolumn{21}{|c|}{22 : 00 Post- entrenamiento } \\
\hline 175 & gr. & $\begin{array}{l}\text { pechuga } \\
\text { de pavo. }\end{array}$ & 183,8 & 42,2 & 1,7 & 1,8 & 0 & 0,6 & 0,4 & 0,4 & 78,8 & 14 & 1,8 & 3,5 & 35 & 3,2 & 39,2 & 80,5 & 582,8 & 0 \\
\hline 250 & gr. & $\begin{array}{l}\text { pisto de } \\
\text { verduras } \\
\text { congelad }\end{array}$ & 141,5 & 7,2 & 0,4 & 21,9 & 11 & 0,1 & 0 & 0,2 & 0 & 62,5 & 2 & 6,3 & 55 & 1,2 & 0,8 & 677,5 & 422,5 & 0 \\
\hline 160 & gr. & $\begin{array}{l}\text { huevo } \\
\text { de } \\
\text { dallina. }\end{array}$ & 259,2 & 20,3 & 19,4 & 1,1 & 0 & 5,3 & 7,8 & 2,9 & 656 & 89,9 & 3,5 & 20,3 & 19,4 & 3,2 & 16 & 230,4 & 235,2 & 176 \\
\hline 50 & gr. & $\begin{array}{l}\text { pan } \\
\text { blanco } \\
\text { sin sal. }\end{array}$ & 132,5 & 4 & 0,6 & 27 & 1,8 & 0,1 & 0 & 0,2 & 0 & 10 & 0,8 & 2,5 & 13 & 0,3 & 11,3 & 1 & 50 & 0 \\
\hline \multirow[t]{3}{*}{50} & gr. & manzana & 27 & 0,2 & 0,2 & 5,7 & 1 & 0 & 0,1 & 0,1 & 0 & 2,8 & 0,3 & 0,6 & 2,8 & 0,1 & 0,7 & 0,6 & 60 & 4,6 \\
\hline & & Total. & 744 & 73,9 & 22,3 & 57,5 & & & & & & & & & & & & & & \\
\hline & & Total día & 4121 & 210,5 & 43,7 & 678,5 & 96,4 & 11,8 & 15,3 & 7,9 & 905,9 & 1764 & 51,9 & 145,2 & 690,1 & 24,4 & 202,4 & 3527 & 8571,3 & 286,2 \\
\hline
\end{tabular}




\section{Día de la competición.}

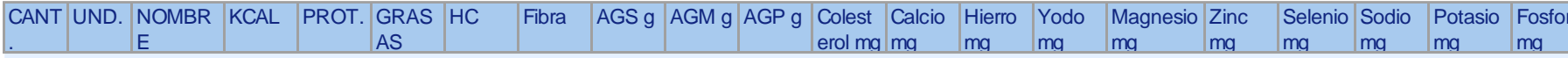
08:00 - Desayuno

\begin{tabular}{|c|c|c|c|c|c|c|c|c|c|c|c|c|c|c|c|c|c|c|c|}
\hline 100 gr. & $\begin{array}{l}\text { leche de } \\
\text { soja. }\end{array}$ & 55 & 3,2 & 1,8 & 5,8 & 1,3 & 0,2 & 0,3 & 0,8 & 0 & 3 & 0,8 & 0 & 28 & 0,4 & 1,3 & 3 & 191 & 0 \\
\hline 100 gr. & manzana & 54,1 & 0,3 & 0,4 & 11,4 & 2 & 0,1 & 0,2 & 0,1 & 0 & 5,5 & 0,6 & 1,1 & 5,6 & 0,1 & 1,4 & 1,2 & 120 & 9,1 \\
\hline \multirow[t]{2}{*}{$60 \mathrm{gr}}$. & $\begin{array}{l}\text { cereales } \\
\text { con base } \\
\text { de maiz }\end{array}$ & 224,4 & 2,7 & 0,4 & 52,2 & 0,9 & 0,1 & 0,1 & 0,2 & 0 & 271,8 & 4,7 & 3 & 3 & 0,1 & 2,6 & 360 & 36 & 0 \\
\hline & Total. & 333,5 & 6,2 & 2,6 & 69,4 & & & & & & & & & & & & & & \\
\hline \multicolumn{20}{|c|}{ 11:00 - Media mañana } \\
\hline 100 gr. & $\begin{array}{l}\text { zumo de } \\
\text { naranja. }\end{array}$ & 43,3 & 0,6 & 0,2 & 9,4 & 0,7 & 0 & 0 & 0 & 0 & 10,8 & 0,2 & 2 & 10,9 & 0,1 & 1 & 1,4 & 150 & 0 \\
\hline \multirow[t]{2}{*}{$50 \mathrm{gr}}$. & $\begin{array}{l}\text { barrita de } \\
\text { cereales } \\
\text { con }\end{array}$ & 196 & 4 & 2,5 & 39 & 0,8 & 1 & 0 & 0 & 0 & 0 & 5,5 & 0 & 0 & 0 & 0 & 0,2 & 0 & 0 \\
\hline & Total. & 239,3 & 4,6 & 2,7 & 48,4 & & & & & & & & & & & & & & \\
\hline \multicolumn{20}{|c|}{ 14:00 - Almuerzo. } \\
\hline $100 \mathrm{gr}$. & platano. & 95 & 1,1 & 0,3 & 20,8 & 2,6 & 0,1 & 0 & 0,1 & 0 & 7,3 & 0,6 & 2,4 & 36,4 & 0,2 & 1,4 & 1 & 370 & 14 \\
\hline $50 \mathrm{gr}$. & $\begin{array}{l}\text { maiz en } \\
\text { grano } \\
\text { hervido }\end{array}$ & 51,2 & 1,7 & 0,6 & 9,1 & 1,2 & 0,1 & 0,2 & 0,3 & 0 & 1,5 & 0,3 & 0,5 & 11 & 0,2 & 0,4 & 152 & 100 & 0 \\
\hline 100 gr. & $\begin{array}{l}\text { champiñ } \\
\text { on en } \\
\text { conserva }\end{array}$ & 21,4 & 3,4 & 0,5 & 0,1 & 1,5 & 0,1 & 0 & 0,2 & 0 & 19 & 0,8 & 2 & 15 & 0,3 & 8,8 & 319 & 121 & 0 \\
\hline 100 gr. & $\begin{array}{l}\text { atun en } \\
\text { aceite. }\end{array}$ & 208 & 24,8 & 12,1 & 0 & 0 & 1,8 & 3,6 & 5,5 & 39,8 & 27,7 & 1,2 & 34,2 & 28,2 & 0,3 & 90 & 291 & 248 & 0 \\
\hline 175 gr. & $\begin{array}{l}\text { solomillo } \\
\text { de } \\
\text { ternera. }\end{array}$ & 180,2 & 35,3 & 4,4 & 1,8 & 0 & 1,9 & 1,6 & 0,6 & 117,2 & 16,1 & 4,6 & 8,6 & 34,3 & 5,4 & 15,2 & 96,3 & 623 & 0 \\
\hline 80 gr. & lechuga. & 15,7 & 1,1 & 0,5 & 1,1 & 1,2 & 0,1 & 0 & 0,3 & 0 & 27,8 & 0,8 & 2,4 & 7 & 0,2 & 0,8 & 2,4 & 176 & 0 \\
\hline $50 \mathrm{gr}$. & $\begin{array}{l}\text { pan } \\
\text { integral. }\end{array}$ & 110,5 & 3,5 & 1,4 & 19 & 3,8 & 0,3 & 0,2 & 0,6 & 0 & 27 & 1,4 & 0,5 & 38 & 0,9 & 17,5 & 275 & 115 & 0 \\
\hline 200 gr. & $\begin{array}{l}\text { macedon } \\
\text { ia de } \\
\text { frutas en }\end{array}$ & 107 & 1,4 & 0,1 & 24,2 & 2 & 0 & 0 & 0 & 0 & 32 & 0,4 & 4 & 24 & 0,2 & 2 & 4 & 420 & 0 \\
\hline \multirow[t]{2}{*}{80 gr. } & tomate. & 17,7 & 0,7 & 0,2 & 2,8 & 1,1 & 0 & 0 & 0,1 & 0 & 8,5 & 0,6 & 1,8 & 6,6 & 0,1 & 0,8 & 7,2 & 193,6 & 19,2 \\
\hline & Total. & 806,7 & 73 & 20,1 & 78,9 & & & & & & & & & & & & & & \\
\hline \multicolumn{20}{|c|}{ 18:00 - Post-competición } \\
\hline 80 gr. & $\begin{array}{l}\text { jamon } \\
\text { serrano. }\end{array}$ & 108,8 & 17,1 & 4,5 & 0 & 0 & 1,5 & 2,2 & 0,5 & 56,7 & 10,2 & 1,8 & 9,1 & 13,7 & 1,8 & 0 & 1872 & 200 & 0 \\
\hline 250 gr. & $\begin{array}{l}\text { yogur } \\
\text { desnatad } \\
\text { o natural. }\end{array}$ & 112,2 & 10,6 & 0,8 & 15,8 & 0 & 0,3 & 0,4 & 0 & 2,5 & 350 & 0,2 & 13,2 & 34,2 & 1,1 & 2,5 & 142,5 & 467,5 & 50 \\
\hline 200 gr. & platano. & 190,1 & 2,1 & 0,5 & 41,6 & 5,1 & 0,2 & 0,1 & 0,2 & 0 & 14,6 & 1,2 & 4,8 & 72,8 & 0,4 & 2,8 & 2 & 740 & 28 \\
\hline 40 gr. & $\begin{array}{l}\text { pastel de } \\
\text { chocolat } \\
\text { e. }\end{array}$ & 177,2 & 2,1 & 11,2 & 16,7 & 0,7 & 6,8 & 3,5 & 0,4 & 59,2 & 12,8 & 0,6 & 0 & 14 & 0,2 & 4,8 & 146 & 56,8 & 0 \\
\hline \multirow[t]{2}{*}{100 gr. } & $\begin{array}{l}\text { pan } \\
\text { blanco } \\
\text { sin sal. }\end{array}$ & 265 & 8 & 1,1 & 53,9 & 3,5 & 0,2 & 0,1 & 0,4 & 0 & 20 & 1,7 & 5 & 26 & 0,6 & 22,6 & 2 & 100 & 0 \\
\hline & Total. & 853,3 & 39,9 & 18,1 & 128 & & & & & & & & & & & & & & \\
\hline \multicolumn{20}{|c|}{ 21:00 - Cena } \\
\hline $125 \mathrm{gr}$. & $\begin{array}{l}\text { yogur } \\
\text { entero } \\
\text { de } \\
\text { sabores. }\end{array}$ & 142,5 & 6,7 & 4,2 & 19,5 & 0 & 2,6 & 1,2 & 0,1 & 13,8 & 151,2 & 0,1 & 7,5 & 17,8 & 0,6 & 1,2 & 81,2 & 300 & 0 \\
\hline \multirow[t]{3}{*}{$400 \mathrm{gr}}$. & $\begin{array}{l}\text { pizza } \\
\text { romana } \\
\text { congelad } \\
\text { a. }\end{array}$ & 708 & 29,2 & 15,1 & 106 & 15 & 8 & 4,3 & 2 & 140,4 & 359,2 & 9,2 & 25,2 & 96,4 & 8 & 22,4 & 3697 & 777,6 & 0 \\
\hline & Total. & 850,5 & 35,9 & 19,3 & 125,5 & & & & & & & & & & & & & & \\
\hline & Total día & 3083 & 159,6 & 62,8 & 450,2 & 43,4 & 25,4 & 18 & 12,4 & 429,6 & 1376 & 37,3 & 127,3 & 522,9 & 21,2 & 199,5 & 7457 & 5505,5 & 120,3 \\
\hline
\end{tabular}


D. Día después de la competición.

\begin{tabular}{|c|c|c|c|c|c|c|c|c|c|c|c|c|c|c|c|c|c|c|c|c|}
\hline CANT UND. & $\begin{array}{l}\text { NOMBR } \\
\text { E }\end{array}$ & KCAL & PROT. & $\begin{array}{l}\text { GRAS } \\
\text { AS }\end{array}$ & $\mathrm{HC}$ & IG & Fibra & AGS $g$ & AGM g & AGP $g$ & $\begin{array}{l}\text { Colest } \\
\text { erol mg }\end{array}$ & $\begin{array}{l}\text { Calcio } \\
\mathrm{mg}\end{array}$ & $\begin{array}{l}\text { Hierro } \\
\mathrm{mg}\end{array}$ & $\begin{array}{l}\text { Yodo } \\
\text { mg }\end{array}$ & $\begin{array}{l}\text { Magnesio } \\
\mathrm{mg}\end{array}$ & $\begin{array}{l}\text { Zinc } \\
\mathrm{mg}\end{array}$ & $\begin{array}{l}\text { Selenio } \\
\mathrm{mg}\end{array}$ & $\begin{array}{l}\text { Sodio } \\
\mathrm{mg}\end{array}$ & $\begin{array}{l}\text { Potasio } \\
\mathrm{mg}\end{array}$ & $\begin{array}{l}\text { Fosforo } \\
\mathrm{mg}\end{array}$ \\
\hline \multicolumn{21}{|c|}{ 09:00 - Desayuno } \\
\hline $50 \mathrm{gr}$. & tomate. & 11,1 & 0,4 & 0,1 & 1,8 & & 0,7 & 0 & 0 & 0 & 0 & 5,3 & 0,4 & 1,1 & 4,2 & 0,1 & 0,5 & 4,5 & 121 & 12 \\
\hline $200 \mathrm{gr}$. & $\begin{array}{l}\text { pan } \\
\text { blanco } \\
\text { sin sal. }\end{array}$ & 530 & 16 & 2,2 & 107,8 & & 7 & 0,4 & 0,2 & 0,8 & 0 & 40 & 3,4 & 10 & 52 & 1,2 & 45,2 & 4 & 200 & 0 \\
\hline $80 \mathrm{gr}$. & $\begin{array}{l}\text { jamon } \\
\text { serrano. }\end{array}$ & 108,8 & 17,1 & 4,5 & 0 & & 0 & 1,5 & 2,2 & 0,5 & $5 \quad 56,7$ & 10,2 & 1,8 & 9,1 & 13,7 & 1,8 & 0 & 1872 & 200 & 0 \\
\hline \multirow[t]{2}{*}{$100 \mathrm{gr}}$. & $\begin{array}{l}\text { zumo de } \\
\text { piña. }\end{array}$ & 41,4 & 0,4 & 0,1 & 9,7 & & 0,2 & 0 & 0 & 0 & 0 & 15 & 0,3 & 1 & 13 & 0,1 & 0,1 & 4,6 & 116 & 0 \\
\hline & Total. & 691,3 & 33,9 & 6,9 & 119,3 & & & & & & & & & & & & & & & \\
\hline \multicolumn{21}{|c|}{ 12:00 - Media mañana } \\
\hline $70 \mathrm{gr}$. & $\begin{array}{l}\text { barrita de } \\
\text { cereales } \\
\text { con }\end{array}$ & 274,4 & 5,6 & 3,5 & 54,6 & & 1 & 1,4 & 0 & 0 & 0 & 0 & 7,7 & 0 & 0 & 0 & 0 & 0,3 & 0 & 0 \\
\hline $200 \mathrm{gr}$. & kiwi. & 103,6 & 2 & 1,6 & 18,2 & & 4,2 & 0,2 & 0,2 & 0,8 & 0 & 68,2 & 0,7 & 0,7 & 29,9 & 0,3 & 1,2 & 8 & 580 & 0 \\
\hline $125 \mathrm{gr}$. & $\begin{array}{l}\text { yogur } \\
\text { liquido }\end{array}$ & 102,4 & 3,5 & 1,9 & 17,9 & & 0 & 1,2 & 0,5 & 1,2 & 1,2 & 137,5 & 0,1 & 5 & 15 & 0,4 & 1,2 & 51,2 & 2173,8 & 0 \\
\hline $100 \mathrm{gr}$. & gelatina. & 338 & 84,4 & 0 & 0 & & 0 & 0 & 0 & 0 & 0 & 11 & 0 & 6 & 11 & 0,2 & 0 & 32 & 22 & 0 \\
\hline & Total. & 818,4 & 95,5 & 7 & 90,7 & & & & & & & & & & & & & & & \\
\hline \multicolumn{21}{|c|}{ 15:00 - Almuerzo. } \\
\hline $100 \mathrm{gr}$. & $\begin{array}{l}\text { fresa y } \\
\text { freson. }\end{array}$ & 32,2 & 0,8 & 0,4 & 5,5 & & 1,7 & 0 & 0,1 & 0,2 & 0 & 21,5 & 0,5 & 2,7 & 13,3 & 0,2 & 1,3 & 1,4 & 161 & 16 \\
\hline $200 \mathrm{gr}$. & $\begin{array}{l}\text { crema } \\
\text { desecad } \\
\text { a de }\end{array}$ & 852 & 16 & 31 & 124,5 & & 4,8 & 17 & 11,8 & 0,6 & 2 & 50,6 & 3,8 & 181,6 & 98,6 & 4,6 & 1,4 & 878 & 3186,4 & 0 \\
\hline 200 gr. & $\begin{array}{l}\text { paella de } \\
\text { marisco } \\
\text { conaelad }\end{array}$ & 248 & 7,1 & 1,2 & 50,3 & & 4,1 & 0,5 & 0,4 & 0,1 & 34 & 40,6 & 1,5 & 22,4 & 46,4 & 0,4 & 21,4 & 858,6 & 428,6 & 0 \\
\hline \multirow[t]{2}{*}{$50 \mathrm{gr}}$. & $\begin{array}{l}\text { pan } \\
\text { blanco } \\
\text { sin sal. }\end{array}$ & 132,5 & 4 & 0,6 & 27 & & 1,8 & 0,1 & 0 & 0,2 & 0 & 10 & 0,8 & 2,5 & 13 & 0,3 & 11,3 & 1 & 50 & 0 \\
\hline & Total. & 1265 & 27,9 & 33,2 & 207,3 & & & & & & & & & & & & & & & \\
\hline \multicolumn{21}{|c|}{ 18:00 - Merienda } \\
\hline 200 gr. & $\begin{array}{l}\text { leche de } \\
\text { vaca } \\
\text { desnatad }\end{array}$ & 74 & 7,8 & 0,4 & 9,8 & & 0 & 0,2 & 0,1 & 0 & 5,2 & 241,8 & 0,2 & 22,2 & 57,2 & 1,1 & 3,2 & 106 & 300 & c \\
\hline \multirow[t]{2}{*}{$100 \mathrm{gr}}$. & $\begin{array}{l}\text { cereales } \\
\text { con base } \\
\text { de maiz. }\end{array}$ & 376 & 8 & 0,8 & 83 & & 2,5 & 0,2 & 0,1 & 0,2 & 0 & 10 & 7,9 & 5 & 15 & 0,2 & 2,6 & 100 & 100 & 0 \\
\hline & & 450 & 15,8 & 1,2 & 92,8 & & & & & & & & & & & & & & & \\
\hline \multicolumn{21}{|l|}{ 21:00 - Cena } \\
\hline $150 \mathrm{gr}$. & abadejo. & 110,8 & 25 & 1,2 & 0 & & 0 & 0,2 & 0,1 & 0,4 & $4 \quad 106,5$ & 12 & 0,3 & 154,5 & 34,5 & 0,6 & 30 & 150 & 507 & c \\
\hline 200 gr. & $\begin{array}{l}\text { patata } \\
\text { vieja. }\end{array}$ & 157,4 & 4,4 & 0,4 & 32,2 & & 3,6 & 0,1 & 0 & 0,2 & 0 & 14,4 & 1,6 & 8,2 & 39,8 & 0,5 & 2 & 14 & 720 & 0 \\
\hline \multirow[t]{3}{*}{$200 \mathrm{gr}}$. & $\begin{array}{l}\text { pera en } \\
\text { almibar. }\end{array}$ & 138,6 & 0,5 & 0,2 & 32,2 & & 3 & 0 & 0 & 0 & 0 & 14 & 0,8 & 2 & 8 & 0,2 & 0,4 & 12,2 & 130 & 5,8 \\
\hline & Total. & 406,8 & $\begin{array}{l}39,9 \\
\end{array}$ & 1,8 & 64,4 & & & & & & & & & & & & & & & \\
\hline & Total & 3631 & 203 & 50,1 & 574,5 & & 34,6 & 23 & $\begin{array}{ll}3 & 15,7\end{array}$ & 5,2 & \begin{tabular}{|l|l|}
205,6
\end{tabular} & 702,1 & 31,8 & 434 & 464,6 & 12,2 & 121,8 & 4098 & 3995,8 & 33,8 \\
\hline
\end{tabular}




\subsubsection{Recuperación.}

\section{A. Día 1.}

CANT UND. NOMBR KCAL PROT. GRAS HC Fibra AGS

08:00 - Desayuno

\begin{tabular}{|c|c|c|c|c|c|c|c|c|c|c|c|c|c|c|c|c|c|c|c|}
\hline $100 \mathrm{gr}$. & $\begin{array}{l}\text { melocoto } \\
\mathrm{n} \text {. }\end{array}$ & 50,8 & 1 & 0,2 & 10,3 & 1,9 & 0 & 0,1 & 0,1 & 0 & 8 & 0,4 & 2,4 & 8,8 & 0,1 & 1,2 & 1,3 & 194 & 12 \\
\hline $100 \mathrm{gr}$. & $\begin{array}{l}\text { zumo de } \\
\text { zanahori } \\
\text { a natural }\end{array}$ & 23,9 & 0,6 & 0,2 & 4,8 & 0,6 & 0 & 0 & 0,1 & 0 & 27 & 0,5 & 7 & 13 & 1 & 0,6 & 52 & 219 & 0 \\
\hline $5 \mathrm{gr}$. & $\begin{array}{l}\text { sal } \\
\text { comun. }\end{array}$ & 0 & 0 & 0 & 0 & 0 & 0 & 0 & 0 & 0 & 1,4 & 0 & 2,2 & 14,5 & 0 & 0 & 1943 & 0 & 0 \\
\hline $6 \mathrm{gr}$. & $\begin{array}{l}\text { aceite de } \\
\text { oliva } \\
\text { viraen. }\end{array}$ & 53,9 & 0,1 & 6 & 0 & 0 & 0,9 & 4,3 & 0,6 & 0 & 0 & 0 & 0 & 0 & 0,1 & 0,1 & 0 & 0 & 0 \\
\hline $40 \mathrm{gr}$. & tomate. & 8,9 & 0,4 & 0,1 & 1,4 & 0,6 & 0 & 0 & 0 & 0 & 4,2 & 0,3 & 0,9 & 3,3 & 0,1 & 0,4 & 3,6 & 96,8 & 9,6 \\
\hline $50 \mathrm{gr}$. & $\begin{array}{l}\text { cereales } \\
\text { con base } \\
\text { de maiz. }\end{array}$ & 188 & 4 & 0,4 & 41,5 & 1,2 & 0,1 & 0,1 & 0,1 & 0 & 5 & 4 & 2,5 & 7,5 & 0,1 & 1,3 & 50 & 50 & 0 \\
\hline $100 \mathrm{gr}$. & $\begin{array}{l}\text { pan } \\
\text { integral } \\
\text { tostado. }\end{array}$ & 265 & 10,8 & 2,9 & 44,5 & 8,7 & 0,6 & 0,6 & 0,9 & 0 & 63 & 3,2 & 1 & 89 & 2,1 & 41 & 640 & 270 & 0 \\
\hline \multirow[t]{2}{*}{$200 \mathrm{gr}}$. & $\begin{array}{l}\text { leche de } \\
\text { soja. }\end{array}$ & 110 & 6,4 & 3,7 & 11,5 & 2,6 & 0,4 & 0,6 & 1,6 & 0 & 6 & 1,6 & 0 & 56 & 0,8 & 2,6 & 6 & 382 & 0 \\
\hline & Total. & 700,5 & 23,3 & 13,5 & 114 & & & & & & & & & & & & & & \\
\hline \multicolumn{20}{|c|}{ 11:00 - Media mañana } \\
\hline $150 \mathrm{gr}$. & gelatina. & 507 & 126,6 & 0 & 0 & 0 & 0 & 0 & 0 & 0 & 16,5 & 0 & 9 & 16,5 & 0,3 & 0 & 48 & 33 & 0 \\
\hline \multirow[t]{2}{*}{$100 \mathrm{gr}$. } & $\begin{array}{l}\text { ciruela } \\
\text { seca. }\end{array}$ & 218,7 & 2,2 & 0,5 & 42,4 & 17,8 & 0 & 0,3 & 0,1 & 0 & 41 & 2,3 & 1 & 27 & 0,4 & 2,7 & 8 & 824 & 0 \\
\hline & Total. & 725,7 & 128,8 & 0,5 & 42,4 & & & & & & & & & & & & & & \\
\hline \multicolumn{20}{|c|}{ 14:00 - Almuerzo } \\
\hline $5 \mathrm{gr}$. & $\begin{array}{l}\text { sal } \\
\text { comun. }\end{array}$ & 0 & 0 & 0 & 0 & 0 & 0 & 0 & 0 & 0 & 1,4 & 0 & 2,2 & 14,5 & 0 & 0 & 1943 & 0 & 0 \\
\hline $150 \mathrm{gr}$. & $\begin{array}{l}\text { pechuga } \\
\text { de pollo. }\end{array}$ & 217,5 & 33,3 & 9,3 & 0 & 0 & 2,9 & 2,9 & 2,3 & 93 & 21 & 1,6 & 10,4 & 31,5 & 1,2 & 9,8 & 99 & 396 & 0 \\
\hline $50 \mathrm{gr}$. & $\begin{array}{l}\text { tomate } \\
\text { triturado. }\end{array}$ & 19 & 1,2 & 0,2 & 2,8 & 0,6 & 0 & 0 & 0,1 & 0 & 30 & 0,5 & 1,1 & 16 & 0,1 & 0,3 & 295 & 580 & 0 \\
\hline $80 \mathrm{gr}$. & tomate. & 17,7 & 0,7 & 0,2 & 2,8 & 1,1 & 0 & 0 & 0,1 & 0 & 8,5 & 0,6 & 1,8 & 6,6 & 0,1 & 0,8 & 7,2 & 193,6 & 19,2 \\
\hline $70 \mathrm{gr}$. & lechuga. & 13,7 & 1 & 0,4 & 1 & 1 & 0,1 & 0 & 0,3 & 0 & 24,3 & 0,7 & 2,1 & 6,1 & 0,2 & 0,7 & 2,1 & 154 & 0 \\
\hline $40 \mathrm{gr}$. & $\begin{array}{l}\text { zanahori } \\
\text { a. }\end{array}$ & 15,8 & 0,5 & 0,1 & 2,8 & 1 & 0 & 0 & 0 & 0 & 10,9 & 0,2 & 2,6 & 4,5 & 0,1 & 0,5 & 24,4 & 128,4 & 7,6 \\
\hline $50 \mathrm{gr}$. & pepino. & 6,6 & 0,3 & 0,1 & 1 & 0,4 & 0 & 0 & 0 & 0 & 9,2 & 0,1 & 0,2 & 3,6 & 0,1 & 0,4 & 1,5 & 70 & 5,5 \\
\hline $100 \mathrm{gr}$. & $\begin{array}{l}\text { macedon } \\
\text { ia de } \\
\text { frutas en }\end{array}$ & 53,5 & 0,7 & 0 & 12,1 & 1 & 0 & 0 & 0 & 0 & 16 & 0,2 & 2 & 12 & 0,1 & 1 & 2 & 210 & 0 \\
\hline $200 \mathrm{gr}$. & arroz. & 728 & 13,3 & 1,8 & 163,2 & 2,8 & 0,4 & 0,5 & 0,6 & 0 & 28 & 1,6 & 28 & 62 & 3 & 14 & 7,8 & 218 & 100 \\
\hline
\end{tabular}

\begin{tabular}{l|l|l|l|l|l|}
\hline Total. & 1072 & 51 & 12,1 & 185,7 \\
\hline
\end{tabular}

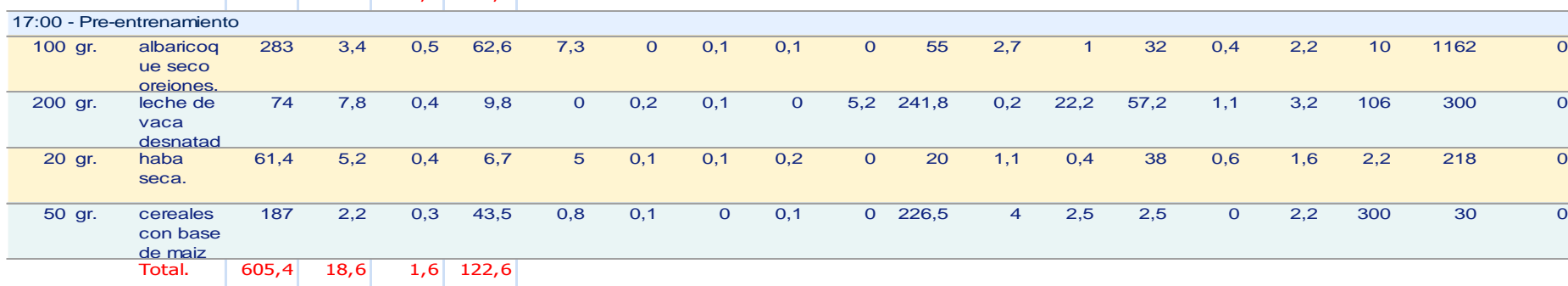

\begin{tabular}{|c|c|c|c|c|c|c|c|c|c|c|c|c|c|c|c|c|c|c|c|}
\hline \multicolumn{20}{|c|}{ 22:00 - Post-entrenamiento } \\
\hline $150 \mathrm{~g}$ & sopa & 528 & 16,8 & 8,2 & 92,8 & 7,5 & 3,8 & 3 & 1,2 & 0 & 36,4 & 3,3 & 24 & 48,4 & 1,7 & 5,3 & 478,8 & 311 & 0 \\
\hline $150 \mathrm{c}$ & $\begin{array}{l}\text { gazpach } \\
\text { o en } \\
\text { conserva }\end{array}$ & 51,6 & 0,9 & 4,2 & 2,4 & 0,3 & 0,7 & 2,8 & 0,5 & 0 & 15 & 0,6 & 1,8 & 4,5 & 0,2 & 2,2 & 454,5 & 138 & 0 \\
\hline $200 \mathrm{~g}$ & manzana & 108,2 & 0,6 & 0,7 & 22,8 & 4 & 0,1 & 0,3 & 0,2 & 0 & 11 & 1,1 & 2,2 & 11,2 & 0,3 & 2,8 & 2,4 & 240 & 18,2 \\
\hline $150 \mathrm{~g}$ & $\begin{array}{l}\text { clara de } \\
\text { huevo. }\end{array}$ & 73,6 & 16,7 & 0,3 & 1 & 0 & 0 & 0 & 0 & 0 & 16,5 & 0,3 & 10,2 & 18 & 0 & 8,1 & 255 & 231 & 0 \\
\hline $175 \mathrm{~g}$ & $\begin{array}{l}\text { pechuga } \\
\text { de pollo. }\end{array}$ & 253,8 & 38,8 & 10,8 & 0 & 0 & 3,3 & 3,4 & 2,7 & 108,5 & 24,5 & 1,9 & 12,1 & 36,8 & 1,4 & 11,4 & 115,5 & 462 & 0 \\
\hline \multirow[t]{3}{*}{100} & $\begin{array}{l}\text { batido de } \\
\text { fresa. }\end{array}$ & 66,6 & 2,8 & 1 & 11,2 & 0,8 & 0,6 & 0,3 & 0 & 12 & 110 & 0,1 & 7,2 & 11,3 & 0,4 & 2,3 & 95 & 183 & 0 \\
\hline & Total. & 1082 & 76,6 & 25,2 & 130,2 & & & & & & & & & & & & & & \\
\hline & Total día & 4185 & 298,3 & 52,9 & 594,9 & 67 & 14,3 & 19,5 & 11,9 & 218,7 & 1078 & 33,1 & 160 & 652,3 & 16 & 118,7 & 6952 & 7293,8 & 172,1 \\
\hline
\end{tabular}




\section{B. Día 2.}

\begin{tabular}{|c|c|c|c|c|c|c|c|c|c|c|c|c|c|c|c|c|c|c|c|c|}
\hline CANT & UND. & $\begin{array}{l}\text { NOMBR } \\
\text { E }\end{array}$ & KCAL & PROT. & $\begin{array}{l}\text { GRAS } \\
\text { AS }\end{array}$ & $\mathrm{HC}$ & Fibra & AGS g & AGM g & AGP g & $\begin{array}{l}\text { Colest } \\
\text { erol mg }\end{array}$ & $\begin{array}{l}\text { Calcio } \\
\mathrm{mg}\end{array}$ & $\begin{array}{l}\text { Hierro } \\
\text { mg }\end{array}$ & $\begin{array}{l}\text { Yodo } \\
\text { mg }\end{array}$ & $\begin{array}{l}\text { Magne } \\
\text { sio mg }\end{array}$ & $\begin{array}{l}\text { Zinc } \\
\text { mg }\end{array}$ & $\begin{array}{l}\text { Selenio } \\
\text { mg }\end{array}$ & $\begin{array}{l}\text { Sodio } \\
\text { mg }\end{array}$ & $\begin{array}{l}\text { Potasio } \\
\text { mg }\end{array}$ & $\begin{array}{l}\text { Fosforo } \\
\text { mg }\end{array}$ \\
\hline \multicolumn{21}{|c|}{ 08:00 - Desayuno } \\
\hline 200 & gr. & $\begin{array}{l}\text { leche de } \\
\text { soja. }\end{array}$ & 110 & 6,4 & 3,7 & 11,5 & 2,6 & 0,4 & 0,6 & 1,6 & 0 & 6 & 1,6 & 0 & 56 & 0,8 & 2,6 & 6 & 382 & \\
\hline 150 & gr. & $\begin{array}{l}\text { pan } \\
\text { blanco } \\
\text { sin sal. }\end{array}$ & 397,5 & 12 & 1,6 & 80,9 & 5,3 & 0,3 & 0,2 & 0,6 & 0 & 30 & 2,6 & 7,5 & 39 & 0,9 & 33,9 & 3 & 150 & \\
\hline 100 & gr. & $\begin{array}{l}\text { mermela } \\
\text { da de } \\
\text { narania. }\end{array}$ & 256,3 & 0,4 & 0 & 63,6 & 0,2 & 0 & 0 & 0 & 0 & 32 & 0,2 & 2,7 & 2 & 0 & 0,6 & 11 & 53 & \\
\hline 200 & gr. & $\begin{array}{l}\text { zumo de } \\
\text { manzana }\end{array}$ & 96,9 & 0,1 & 0,2 & 23,7 & 0 & 0 & 0 & 0,1 & 0 & 13,8 & 0,5 & 2 & 8,4 & 0,2 & 0,2 & 4,4 & 232 & 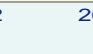 \\
\hline \multirow[t]{2}{*}{50} & gr. & $\begin{array}{l}\text { cereales } \\
\text { con base } \\
\text { de maiz. }\end{array}$ & 188 & 4 & 0,4 & 41,5 & 1,2 & 0,1 & 0,1 & 0,1 & 0 & 5 & 4 & 2,5 & 7,5 & 0,1 & 1,3 & 50 & 50 & \\
\hline & & Total. & 1049 & 22,9 & 5,9 & 221,2 & & & & & & & & & & & & & & \\
\hline
\end{tabular}

\begin{tabular}{|c|c|c|c|c|c|c|c|c|c|c|c|c|c|c|c|c|c|c|c|}
\hline & Total. & 507 & 126,6 & 0 & 0 & & & & & & & & & & & & & & \\
\hline \multicolumn{20}{|c|}{ 14:00 - Almuerzo } \\
\hline 60 gr. & $\begin{array}{l}\text { remolach } \\
\text { a. }\end{array}$ & 27,7 & 0,9 & 0,1 & 5 & 1,5 & 0 & 0 & 0 & 0 & 10,2 & 0,5 & 0,2 & 12,6 & 0,2 & 0,4 & 34,8 & 244,2 & 7,2 \\
\hline $5 \mathrm{gr}$. & vinagre. & 0,2 & 0 & 0 & 0 & 0 & 0 & 0 & 0 & 0 & 0,8 & 0 & 0 & 1,1 & 0 & 0 & 1 & 4,4 & 0 \\
\hline $5 \mathrm{gr}$. & $\begin{array}{l}\text { aceite de } \\
\text { Oliva }\end{array}$ & 45 & 0 & 5 & 0 & 0 & 0,7 & 3,6 & 0,5 & 0 & 0 & 0 & 0 & 0 & 0 & 0 & 0 & 0 & 0 \\
\hline $40 \mathrm{gr}$. & lechuga. & 7,8 & 0,5 & 0,2 & 0,6 & 0,6 & 0 & 0 & 0,1 & 0 & 13,9 & 0,4 & 1,2 & 3,5 & 0,1 & 0,4 & 1,2 & 88 & 0 \\
\hline 85 gr. & tomate. & 18,8 & 0,7 & 0,2 & 3 & 1,2 & 0 & 0 & 0,1 & 0 & 9 & 0,6 & 1,9 & 7,1 & 0,1 & 0,8 & 7,6 & 205,7 & 20,4 \\
\hline 50 gr. & $\begin{array}{l}\text { atun al } \\
\text { natural. }\end{array}$ & 49,7 & 11,8 & 0,3 & 0 & 0 & 0,1 & 0 & 0,1 & 25,5 & 14 & 0,5 & 6,5 & 13,5 & 0,4 & 40,2 & 160 & 115 & 0 \\
\hline $100 \mathrm{gr}$. & pasta. & 359 & 12,8 & 1,6 & 70,9 & 5 & 0,2 & 0,2 & 0,6 & 0 & 24 & 1,8 & 10 & 48 & 1,2 & 62,2 & 7 & 236 & 0 \\
\hline $100 \mathrm{gr}$. & pera. & 49,4 & 0,4 & 0,1 & 10,6 & 2,2 & 0 & 0 & 0 & 0 & 9,6 & 0,3 & 2,1 & 8,4 & 0,2 & 0,6 & 2,1 & 116 & 9,9 \\
\hline $30 \mathrm{gr}$. & $\begin{array}{l}\text { tomate } \\
\text { triturado. }\end{array}$ & 11,4 & 0,7 & 0,2 & 1,7 & 0,4 & 0 & 0 & 0,1 & 0 & 18 & 0,3 & 0,7 & 9,6 & 0,1 & 0,2 & 177 & 348 & 0 \\
\hline $150 \mathrm{gr}$. & $\begin{array}{l}\text { solomillo } \\
\text { de } \\
\text { ternera. }\end{array}$ & 154,5 & 30,3 & 3,8 & 1,5 & 0 & 1,6 & 1,4 & 0,5 & 100,5 & 13,8 & 3,9 & 7,4 & 29,4 & 4,6 & 13 & 82,5 & 534 & 0 \\
\hline $5 \mathrm{gr}$. & $\begin{array}{l}\text { sal } \\
\text { comun. }\end{array}$ & 0 & 0 & 0 & 0 & 0 & 0 & 0 & 0 & 0 & 1,4 & 0 & 2,2 & 14,5 & 0 & 0 & 1943 & 0 & 0 \\
\hline $20 \mathrm{gr}$. & $\begin{array}{l}\text { pan } \\
\text { integral. }\end{array}$ & 44,2 & 1,4 & 0,6 & 7,6 & 1,5 & 0,1 & 0,1 & 0,2 & 0 & 10,8 & 0,5 & 0,2 & 15,2 & 0,4 & 7 & 110 & 46 & 0 \\
\hline $20 \mathrm{gr}$. & $\begin{array}{l}\text { almendra } \\
\text { sin } \\
\text { cascara }\end{array}$ & 122 & 3,7 & 10,8 & 1,1 & 2,7 & 0,8 & 6,6 & 2,6 & 0 & 50,4 & 0,8 & 0,4 & 54 & 0,6 & 0,7 & 2,8 & 167 & 18 \\
\hline \multirow[t]{2}{*}{$50 \mathrm{gr}$. } & $\begin{array}{l}\text { pan } \\
\text { blanco } \\
\text { tipo }\end{array}$ & 129 & 4,8 & 0,6 & 25,3 & 1,8 & 0,1 & 0 & 0,2 & 0 & 11,5 & 0,8 & 3 & 14 & 0,4 & 14 & 285 & 65 & 0 \\
\hline & Total. & 1019 & 68 & 23,5 & 127,3 & & & & & & & & & & & & & & \\
\hline \multicolumn{20}{|c|}{ 17:00 - Pre-entrenamiento } \\
\hline $50 \mathrm{gr}$. & $\begin{array}{l}\text { barrita de } \\
\text { cereales } \\
\text { con }\end{array}$ & 196 & 4 & 2,5 & 39 & 0,8 & 1 & 0 & 0 & 0 & 0 & 5,5 & 0 & 0 & 0 & 0 & 0,2 & 0 & 0 \\
\hline $125 \mathrm{gr}$. & $\begin{array}{l}\text { yogur } \\
\text { desnatad } \\
\text { o natural. }\end{array}$ & 56,1 & 5,3 & 0,4 & 7,9 & 0 & 0,1 & 0,2 & 0 & 1,2 & 175 & 0,1 & 6,6 & 17,1 & 0,6 & 1,2 & 71,2 & 233,8 & 25 \\
\hline $200 \mathrm{gr}$. & manzana & 108,2 & 0,6 & 0,7 & 22,8 & 4 & 0,1 & 0,3 & 0,2 & 0 & 11 & 1,1 & 2,2 & 11,2 & 0,3 & 2,8 & 2,4 & 240 & 18,2 \\
\hline & Total. & 360,3 & 9,9 & 3,6 & 69,7 & & & & & & & & & & & & & & \\
\hline \multicolumn{20}{|c|}{ 22:00 - Post-entrenamiento } \\
\hline $100 \mathrm{gr}$. & kiwi. & 51,8 & 1 & 0,8 & 9,1 & 2,1 & 0,1 & 0,1 & 0,4 & 0 & 34,1 & 0,4 & 0,3 & 14,9 & 0,2 & 0,6 & 4 & 290 & 0 \\
\hline $150 \mathrm{gr}$. & $\begin{array}{l}\text { pechuga } \\
\text { de pollo. }\end{array}$ & 217,5 & 33,3 & 9,3 & 0 & 0 & 2,9 & 2,9 & 2,3 & 93 & 21 & 1,6 & 10,4 & 31,5 & 1,2 & 9,8 & 99 & 396 & 0 \\
\hline $50 \mathrm{gr}$. & $\begin{array}{l}\text { pan } \\
\text { integral. }\end{array}$ & 110,5 & 3,5 & 1,4 & 19 & 3,8 & 0,3 & 0,2 & 0,6 & 0 & 27 & 1,4 & 0,5 & 38 & 0,9 & 17,5 & 275 & 115 & 0 \\
\hline $150 \mathrm{gr}$. & $\begin{array}{l}\text { patata } \\
\text { nueva. }\end{array}$ & 110,4 & 3,5 & 0,2 & 22,2 & 3,1 & 0 & 0 & 0,1 & 0 & 9,6 & 0,6 & 3,9 & 31,5 & 0,5 & 2,2 & 4,1 & 627 & 14,6 \\
\hline $130 \mathrm{gr}$. & $\begin{array}{l}\text { tomate } \\
\text { triturado. }\end{array}$ & 49,5 & 3 & 0,6 & 7,2 & 1,6 & 0,1 & 0,1 & 0,3 & 0 & 78 & 1,3 & 2,9 & 41,6 & 0,4 & 0,8 & 767 & 1508 & 0 \\
\hline $125 \mathrm{gr}$. & $\begin{array}{l}\text { zanahori } \\
\text { a. }\end{array}$ & 49,2 & 1,6 & 0,2 & 8,6 & 3,3 & 0 & 0 & 0,2 & 0 & 34 & 0,6 & 8,2 & 14 & 0,4 & 1,6 & 76,2 & 401,2 & 23,8 \\
\hline $100 \mathrm{gr}$. & arroz. & 364 & 6,7 & 0,9 & 81,6 & 1,4 & 0,2 & 0,2 & 0,3 & 0 & 14 & 0,8 & 14 & 31 & 1,5 & 7 & 3,9 & 109 & 50 \\
\hline $150 \mathrm{gr}$. & $\begin{array}{l}\text { calabaci } \\
\text { n. }\end{array}$ & 34,8 & 2,8 & 0,8 & 3 & 2,4 & 0,2 & 0,2 & 0,2 & 0 & 32,3 & 1 & 3 & 19,3 & 0,4 & 1,5 & 1,5 & 345 & 0 \\
\hline & Total. & 987,7 & 55,4 & 14,2 & 150,7 & & & & & & & & & & & & & & \\
\hline & Total día & 3922 & 282,8 & 47,2 & 568,9 & 48,7 & 9,4 & 17 & 12 & 220,2 & 726,7 & 33,7 & 111,5 & 610,4 & 17 & 223,1 & 4240 & 7334,3 & 207,1 \\
\hline
\end{tabular}




\section{Día 3.}

\begin{tabular}{|c|c|c|c|c|c|c|c|c|c|c|c|c|c|c|c|c|c|c|c|}
\hline CANT UND. & $\begin{array}{l}\text { NOMBR } \\
E\end{array}$ & KCAL & PROT. & $\begin{array}{l}\text { GRAS } \\
\text { AS }\end{array}$ & $\mathrm{HC}$ & Fibra & AGS $\mathrm{g}$ & AGM g & AGP $g$ & $\begin{array}{l}\text { Colest } \\
\text { erol mg }\end{array}$ & $\begin{array}{l}\text { Calcio } \\
\mathrm{mg}\end{array}$ & $\begin{array}{l}\text { Hierro } \\
\mathrm{mg}\end{array}$ & $\begin{array}{l}\text { Yodo } \\
\text { mg }\end{array}$ & $\begin{array}{l}\text { Magne } \\
\text { sio mg }\end{array}$ & $\begin{array}{l}\text { Zinc } \\
\mathrm{mg}\end{array}$ & $\begin{array}{l}\text { Selenio } \\
\mathrm{mg}\end{array}$ & $\begin{array}{l}\text { Sodio } \\
\text { mg }\end{array}$ & $\begin{array}{l}\text { Potasio } \\
\text { mg }\end{array}$ & $\begin{array}{l}\text { Fosforo } \\
\mathrm{mg}\end{array}$ \\
\hline \multicolumn{20}{|c|}{ 08:00 - Desayuno } \\
\hline 200 gr. & $\begin{array}{l}\text { zumo de } \\
\text { manzana }\end{array}$ & 96,9 & 0,1 & 0,2 & 23,7 & 0 & 0 & 0 & 0,1 & 0 & 13,8 & 0,5 & 2 & 8,4 & 0,2 & 0,2 & 4,4 & 232 & 20 \\
\hline $50 \mathrm{gr}$. & $\begin{array}{l}\text { cereales } \\
\text { con base } \\
\text { de maiz. }\end{array}$ & 188 & 4 & 0,4 & 41,5 & 1,2 & 0,1 & 0,1 & 0,1 & 0 & 5 & 4 & 2,5 & 7,5 & 0,1 & 1,3 & 50 & 50 & 0 \\
\hline $50 \mathrm{gr}$. & $\begin{array}{l}\text { haba } \\
\text { seca. }\end{array}$ & 153,5 & 13 & 1 & 16,6 & 12,5 & 0,2 & 0,2 & 0,6 & 0 & 50 & 2,8 & 1 & 95 & 1,6 & 4,1 & 5,5 & 545 & 0 \\
\hline $200 \mathrm{gr}$. & $\begin{array}{l}\text { leche de } \\
\text { soja. }\end{array}$ & 110 & 6,4 & 3,7 & 11,5 & 2,6 & 0,4 & 0,6 & 1,6 & 0 & 6 & 1,6 & 0 & 56 & 0,8 & 2,6 & 6 & 382 & 0 \\
\hline & Total. & 548,4 & 23,5 & 5,3 & 93,3 & & & & & & & & & & & & & & \\
\hline \multicolumn{20}{|c|}{11.00 - Media mañana } \\
\hline 100 gr. & gelatina. & 338 & 84,4 & 0 & 0 & 0 & 0 & 0 & 0 & 0 & 11 & 0 & 6 & 11 & 0,2 & 0 & 32 & 22 & 0 \\
\hline 100 gr. & platano. & 95 & 1,1 & 0,3 & 20,8 & 2,6 & 0,1 & 0 & 0,1 & 0 & 7,3 & 0,6 & 2,4 & 36,4 & 0,2 & 1,4 & 1 & 370 & 14 \\
\hline & Total. & 433 & 85,5 & 0,3 & 20,8 & & & & & & & & & & & & & & \\
\hline \multicolumn{20}{|c|}{ 14:00 - Almuerzo } \\
\hline 150 gr. & $\begin{array}{l}\text { atun al } \\
\text { natural. }\end{array}$ & 149,1 & 35,2 & 0,9 & 0 & 0 & 0,3 & 0,2 & 0,3 & 76,5 & 42 & 1,5 & 19,5 & 40,5 & 1 & 120,6 & 480 & 345 & 0 \\
\hline $200 \mathrm{gr}$. & arroz. & 728 & 13,3 & 1,8 & 163,2 & 2,8 & 0,4 & 0,5 & 0,6 & 0 & 28 & 1,6 & 28 & 62 & 3 & 14 & 7,8 & 218 & 100 \\
\hline $50 \mathrm{gr}$. & $\begin{array}{l}\text { garbanzo } \\
\text { en } \\
\text { conserva }\end{array}$ & 60 & 3,6 & 1,4 & 7,1 & 2 & 0,2 & 0,4 & 0,6 & 0 & 21,5 & 1,4 & 0,5 & 12 & 0,6 & 0,5 & 110 & 55 & 0 \\
\hline $60 \mathrm{gr}$. & espinaca & 12,4 & 1,6 & 0,2 & 0,4 & 1,5 & 0 & 0 & 0,1 & 0 & 70,2 & 1,6 & 7,2 & 36 & 0,4 & 0,5 & 41,4 & 332,4 & 45 \\
\hline $80 \mathrm{gr}$. & tomate. & 17,7 & 0,7 & 0,2 & 2,8 & 1,1 & 0 & 0 & 0,1 & 0 & 8,5 & 0,6 & 1,8 & 6,6 & 0,1 & 0,8 & 7,2 & 193,6 & 19,2 \\
\hline 50 gr. & niscalo. & 11,9 & 0,8 & 0,4 & 0,1 & 2,4 & 0 & 0 & 0,2 & 0 & 4 & 3,2 & 8 & 7 & 0,2 & 3,5 & 1,5 & 253,5 & 0 \\
\hline $60 \mathrm{gr}$. & lechuga. & 11,8 & 0,8 & 0,4 & 0,8 & 0,9 & 0,1 & 0 & 0,2 & 0 & 20,8 & 0,6 & 1,8 & 5,2 & 0,1 & 0,6 & 1,8 & 132 & 0 \\
\hline 70 gr. & $\begin{array}{l}\text { zanahori } \\
\text { a. }\end{array}$ & 27,6 & 0,9 & 0,1 & 4,8 & 1,8 & 0 & 0 & 0,1 & 0 & 19,1 & 0,3 & 4,6 & 7,9 & 0,2 & 0,9 & 42,7 & 224,7 & 13,3 \\
\hline 50 gr. & $\begin{array}{l}\text { pan } \\
\text { blanco } \\
\text { sin sal. }\end{array}$ & 132,5 & 4 & 0,6 & 27 & 1,8 & 0,1 & 0 & 0,2 & 0 & 10 & 0,8 & 2,5 & 13 & 0,3 & 11,3 & 1 & 50 & 0 \\
\hline 150 gr. & $\begin{array}{l}\text { piña en } \\
\text { su jugo. }\end{array}$ & 64,3 & 0,6 & 0,2 & 14,6 & 1,2 & 0,1 & 0 & 0 & 0 & 22,5 & 0,4 & 1,5 & 19,5 & 0,1 & 0,6 & 6,9 & 174 & 0 \\
\hline 90 gr. & $\begin{array}{l}\text { berenjen } \\
\text { a. }\end{array}$ & 18,9 & 1,1 & 0,2 & 2,2 & 2,2 & 0 & 0 & 0,1 & 0 & 14,8 & 0,4 & 1,3 & 9,8 & 0,2 & 0,9 & 2,7 & 189 & 0 \\
\hline & Total. & 1301 & 68 & 6,8 & 231,6 & & & & & & & & & & & & & & \\
\hline \multicolumn{20}{|c|}{ 17:00 - Pre-entrenamiento } \\
\hline 50 gr. & $\begin{array}{l}\text { barrita de } \\
\text { cereales } \\
\text { con }\end{array}$ & 196 & 4 & 2,5 & 39 & 0,8 & 1 & 0 & 0 & 0 & 0 & 5,5 & 0 & 0 & 0 & 0 & 0,2 & 0 & 0 \\
\hline 100 gr. & melon. & 55,4 & 0,9 & 0,1 & 12,4 & 0,7 & 0 & 0 & 0 & 0 & 15,6 & 0,4 & 0,6 & 11,8 & 0,3 & 0,5 & 17 & 310 & 0 \\
\hline $60 \mathrm{gr}$. & te. & 132 & 11,8 & 1,2 & 1,8 & 33,5 & 0,3 & 0,1 & 0,5 & 0 & 181,2 & 10,2 & 6,6 & 110,4 & 1,9 & 3,2 & 8,4 & 984 & 5,7 \\
\hline & Total. & 383,4 & 16,7 & 3,8 & 53,2 & & & & & & & & & & & & & & \\
\hline \multicolumn{20}{|c|}{ 22:00 - Post-enternamiento } \\
\hline $125 \mathrm{gr}$. & $\begin{array}{l}\text { patata } \\
\text { vieja. }\end{array}$ & 98,4 & 2,8 & 0,3 & 20,1 & 2,3 & 0,1 & 0 & 0,1 & 0 & 9 & 1 & 5,1 & 24,9 & 0,3 & 1,2 & 8,8 & 450 & 0 \\
\hline 200 gr. & $\begin{array}{l}\text { sopa } \\
\text { jardinera } \\
\text { para }\end{array}$ & 704 & 22,4 & 11 & 123,8 & 10 & 5 & 4,1 & 1,5 & 0 & 48,6 & 4,4 & 32 & 64,6 & 2,3 & 7 & 638,4 & 414,6 & 0 \\
\hline $100 \mathrm{gr}$. & sandia. & 28,4 & 0,6 & 0,3 & 5,6 & 0,4 & 0,1 & 0 & 0,1 & 0 & 6,7 & 0,3 & 1,5 & 9,2 & 0,2 & 0,4 & 2 & 100 & 11 \\
\hline $80 \mathrm{gr}$. & bonito. & 122,4 & 19,8 & 4,8 & 0 & 0 & 1,2 & 1 & 2,1 & 36 & 6,4 & 1 & 8 & 18,4 & 0,6 & 65,6 & 31,2 & 264 & 22,4 \\
\hline & Total. & 953,2 & 45,6 & 16,4 & 149,5 & & & & & & & & & & & & & & \\
\hline
\end{tabular}




\section{Día 4.}

CANT UND. NOMBR KCAL PROT. GRAS HC Fibra AGS g AGM g AGP g Colest Calcio Hierro Yodo Magne Zinc Selenio Sodio Potasio Fosforo

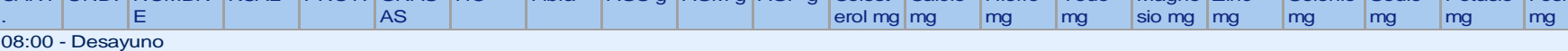

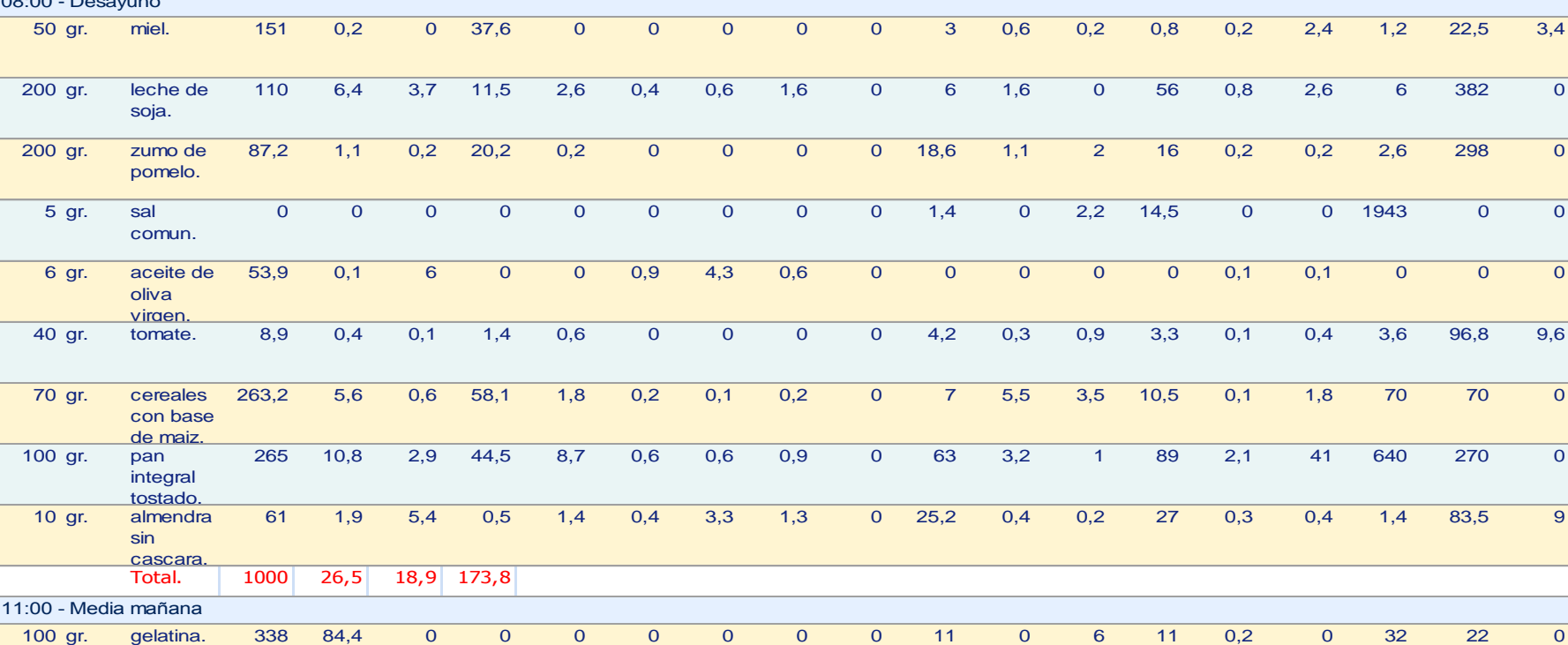

11:00 - Media mañana

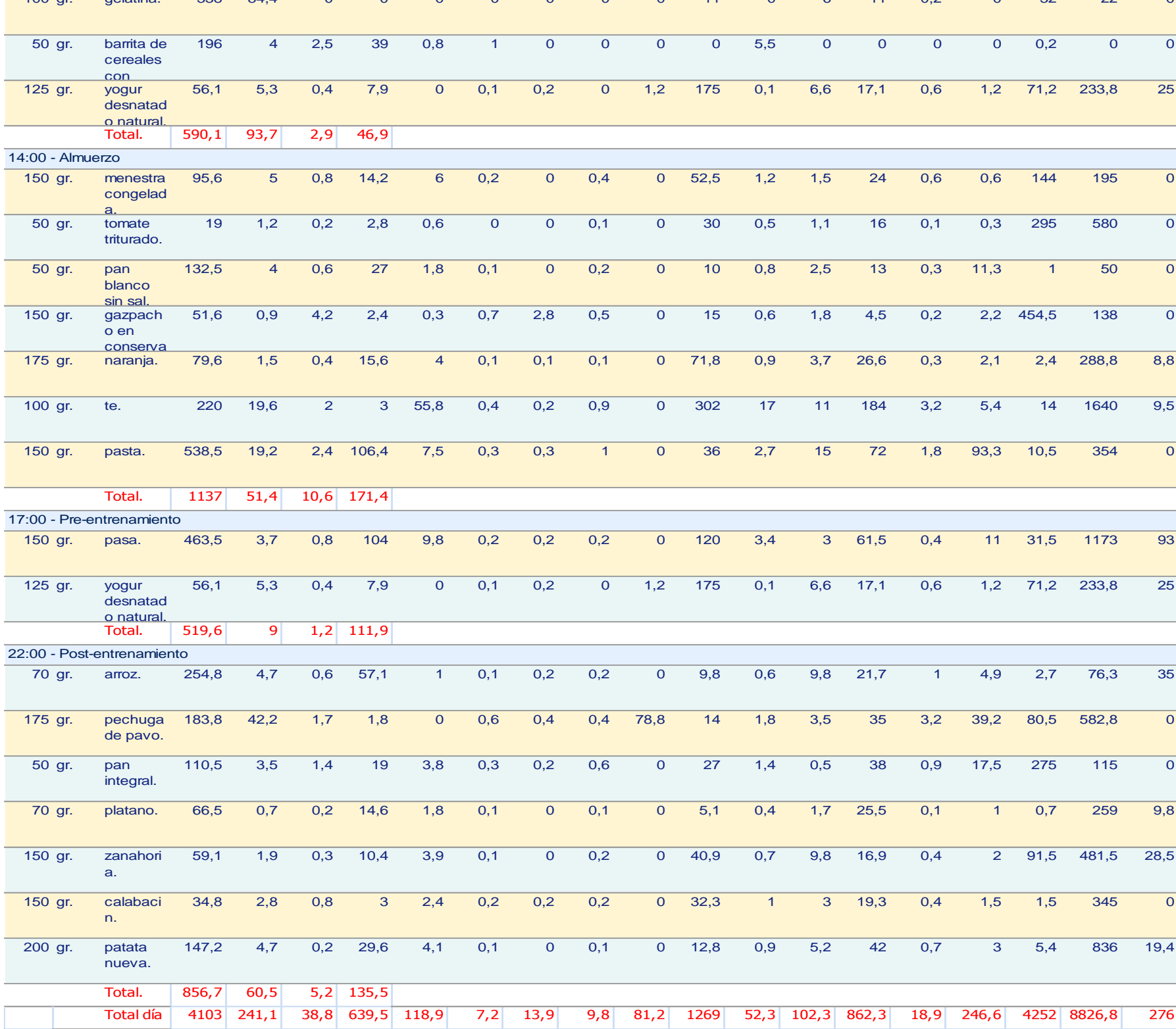




\subsubsection{Lesión.}

\section{A. Día 1.}

\begin{tabular}{|c|c|c|c|c|c|c|c|c|c|c|c|c|c|c|c|c|c|c|c|c|}
\hline CANT & $\begin{array}{l}\mathrm{U} \\
\mathrm{N}\end{array}$ & $\begin{array}{l}\text { NOMBR } \\
E\end{array}$ & KCAL & PROT. & $\begin{array}{l}\text { GRAS } \\
\text { AS }\end{array}$ & $\mathrm{HC}$ & Fibra & AGS $g$ & AGM g & AGP $g$ & $\begin{array}{l}\text { Colest } \\
\text { erol mg }\end{array}$ & $\begin{array}{l}\text { Calcio } \\
\mathrm{mg}\end{array}$ & $\begin{array}{l}\text { Hierro } \\
\text { mg }\end{array}$ & $\begin{array}{l}\text { Yodo } \\
\text { mg }\end{array}$ & $\begin{array}{l}\text { Magne } \\
\text { sio mg }\end{array}$ & $\begin{array}{l}\text { Zinc } \\
\text { mg }\end{array}$ & $\begin{array}{l}\text { Selenio } \\
\text { mg }\end{array}$ & $\begin{array}{l}\text { Sodio } \\
\text { mg }\end{array}$ & $\begin{array}{l}\text { Potasio } \\
\text { mg }\end{array}$ & $\begin{array}{l}\text { Fosforo } \\
\text { mg }\end{array}$ \\
\hline \multicolumn{21}{|c|}{ 08:00 - Desayuno } \\
\hline 150 & gr. & $\begin{array}{l}\text { zumo de } \\
\text { manzana }\end{array}$ & 72,7 & 0,1 & 0,2 & 17,8 & 0 & 0 & 0 & 0,1 & 0 & 10,4 & 0,4 & 1,5 & 6,3 & 0,2 & 0,2 & 3,3 & 174 & 15 \\
\hline 50 & gr. & $\begin{array}{l}\text { cereales } \\
\text { con base } \\
\text { de maiz. }\end{array}$ & 188 & 4 & 0,4 & 41,5 & 1,2 & 0,1 & 0,1 & 0,1 & 0 & 5 & 4 & 2,5 & 7,5 & 0,1 & 1,3 & 50 & 50 & 0 \\
\hline 90 & gr. & $\begin{array}{l}\text { pan } \\
\text { blanco } \\
\text { sin sal. }\end{array}$ & 238,5 & 7,2 & 1 & 48,5 & 3,2 & 0,2 & 0,1 & 0,4 & 0 & 18 & 1,5 & 4,5 & 23,4 & 0,5 & 20,3 & 1,8 & 90 & 0 \\
\hline 100 & gr. & $\begin{array}{l}\text { leche de } \\
\text { soja. }\end{array}$ & 55 & 3,2 & 1,8 & 5,8 & 1,3 & 0,2 & 0,3 & 0,8 & 0 & 3 & 0,8 & 0 & 28 & 0,4 & 1,3 & 3 & 191 & 0 \\
\hline \multirow[t]{2}{*}{30} & gr. & $\begin{array}{l}\text { mermela } \\
\text { da de } \\
\text { narania. }\end{array}$ & 76,9 & 0,1 & 0 & 19,1 & 0,1 & 0 & 0 & 0 & 0 & 9,6 & 0 & 0,8 & 0,6 & 0 & 0,2 & 3,3 & 15,9 & 0 \\
\hline & & Total. & 631,1 & 14,6 & 3,4 & 132,7 & & & & & & & & & & & & & & \\
\hline \multicolumn{21}{|c|}{11.00 - Media mañana } \\
\hline \multirow[t]{2}{*}{250} & gr. & $\begin{array}{l}\text { yogur } \\
\text { desnatad } \\
\text { o natural. }\end{array}$ & 112,2 & 10,6 & 0,8 & 15,8 & 0 & 0,3 & 0,4 & 0 & 2,5 & 350 & 0,2 & 13,2 & 34,2 & 1,1 & 2,5 & 142,5 & 467,5 & 50 \\
\hline & & Total. & 112,2 & 10,6 & 0,8 & 15,8 & & & & & & & & & & & & & & \\
\hline
\end{tabular}

\begin{tabular}{|c|c|c|c|c|c|c|c|c|c|c|c|c|c|c|c|c|c|c|}
\hline 14:00 - Almuerzo & & & & & & & & & & & & & & & & & & \\
\hline 5 gr. vinagre. & 0,2 & 0 & 0 & 0 & 0 & 0 & 0 & 0 & 0 & 0,8 & 0 & 0 & 1,1 & 0 & 0 & 1 & 4,4 & 0 \\
\hline $\begin{array}{l}100 \text { gr. gazpach } \\
\text { o en } \\
\text { conserva }\end{array}$ & 34,4 & 0,6 & 2,8 & 1,6 & 0,2 & 0,5 & 1,9 & 0,3 & 0 & 10 & 0,4 & 1,2 & 3 & 0,1 & 1,5 & 303 & 92 & 0 \\
\hline 80 gr. naranja. & 36,4 & 0,7 & 0,2 & 7,1 & 1,8 & 0 & 0 & 0,1 & 0 & 32,8 & 0,4 & 1,7 & 12,2 & 0,1 & 1 & 1,1 & 132 & 4 \\
\hline $\begin{array}{l}60 \text { gr. remolach } \\
\text { a. }\end{array}$ & 27,7 & 0,9 & 0,1 & 5 & 1,5 & 0 & 0 & 0 & 0 & 10,2 & 0,5 & 0,2 & 12,6 & 0,2 & 0,4 & 34,8 & 244,2 & 7,2 \\
\hline $\begin{array}{c}5 \text { gr. aceite de } \\
\text { oliva } \\
\text { viraen. }\end{array}$ & 45 & 0 & 5 & 0 & 0 & 0,7 & 3,6 & 0,5 & 0 & 0 & 0 & 0 & 0 & 0 & 0 & 0 & 0 & 0 \\
\hline 40 gr. lechuga. & 7,8 & 0,5 & 0,2 & 0,6 & 0,6 & 0 & 0 & 0,1 & 0 & 13,9 & 0,4 & 1,2 & 3,5 & 0,1 & 0,4 & 1,2 & 88 & 0 \\
\hline $85 \mathrm{gr}$. tomate. & 18,8 & 0,7 & 0,2 & 3 & 1,2 & 0 & 0 & 0,1 & 0 & 9 & 0,6 & 1,9 & 7,1 & 0,1 & 0,8 & 7,6 & 205,7 & 20,4 \\
\hline $\begin{array}{l}50 \text { gr. atun al } \\
\text { natural. }\end{array}$ & 49,7 & 11,8 & 0,3 & 0 & 0 & 0,1 & 0 & 0,1 & 25,5 & 14 & 0,5 & 6,5 & 13,5 & 0,4 & 40,2 & 160 & 115 & 0 \\
\hline 100 gr. pasta. & 359 & 12,8 & 1,6 & 70,9 & 5 & 0,2 & 0,2 & 0,6 & 0 & 24 & 1,8 & 10 & 48 & 1,2 & 62,2 & 7 & 236 & 0 \\
\hline 100 gr. pera. & 49,4 & 0,4 & 0,1 & 10,6 & 2,2 & 0 & 0 & 0 & 0 & 9,6 & 0,3 & 2,1 & 8,4 & 0,2 & 0,6 & 2,1 & 116 & 9,9 \\
\hline $\begin{array}{l}30 \text { gr. tomate } \\
\text { triturado. }\end{array}$ & 11,4 & 0,7 & 0,2 & 1,7 & 0,4 & 0 & 0 & 0,1 & 0 & 18 & 0,3 & 0,7 & 9,6 & 0,1 & 0,2 & 177 & 348 & 0 \\
\hline $\begin{array}{l}150 \mathrm{gr} \text {. solomillo } \\
\text { de } \\
\text { ternera. }\end{array}$ & 154,5 & 30,3 & 3,8 & 1,5 & 0 & 1,6 & 1,4 & 0,5 & 100,5 & 13,8 & 3,9 & 7,4 & 29,4 & 4,6 & 13 & 82,5 & 534 & 0 \\
\hline $\begin{array}{l}5 \mathrm{gr} \text {. sal } \\
\text { comun. }\end{array}$ & 0 & 0 & 0 & 0 & 0 & 0 & 0 & 0 & 0 & 1,4 & 0 & 2,2 & 14,5 & 0 & 0 & 1943 & 0 & 0 \\
\hline $\begin{array}{c}50 \text { gr. pan } \\
\text { blanco } \\
\text { tipo }\end{array}$ & 129 & 4,8 & 0,6 & 25,3 & 1,8 & 0,1 & 0 & 0,2 & 0 & 11,5 & 0,8 & 3 & 14 & 0,4 & 14 & 285 & 65 & 0 \\
\hline Total. & 923,3 & 64,2 & 15,1 & 127,3 & & & & & & & & & & & & & & \\
\hline 17:00 Merienda & & & & & & & & & & & & & & & & & & \\
\hline $\begin{array}{l}80 \text { gr. atun al } \\
\text { natural. }\end{array}$ & 79,5 & 18,8 & 0,5 & 0 & 0 & 0,2 & 0,1 & 0,2 & 40,8 & 22,4 & 0,8 & 10,4 & 21,6 & 0,6 & 64,3 & 256 & 184 & 0 \\
\hline $\begin{array}{l}50 \text { gr. pan } \\
\text { integral. }\end{array}$ & 110,5 & 3,5 & 1,4 & 19 & 3,8 & 0,3 & 0,2 & 0,6 & 0 & 27 & 1,4 & 0,5 & 38 & 0,9 & 17,5 & 275 & 115 & 0 \\
\hline Total. & 190 & 22,3 & 1,9 & 19 & & & & & & & & & & & & & & \\
\hline
\end{tabular}

\begin{tabular}{|c|c|c|c|c|c|c|c|c|c|c|c|c|c|c|c|c|c|c|c|c|}
\hline \multicolumn{21}{|c|}{ 21:00 - Cena } \\
\hline 80 & gr. & bonito. & 122,4 & 19,8 & 4,8 & 0 & 0 & 1,2 & 1 & 2,1 & 36 & 6,4 & 1 & 8 & 18,4 & 0,6 & 65,6 & 31,2 & 264 & 22,4 \\
\hline 125 & gr. & $\begin{array}{l}\text { patata } \\
\text { vieja. }\end{array}$ & 98,4 & 2,8 & 0,3 & 20,1 & 2,3 & 0,1 & 0 & 0,1 & 0 & 9 & 1 & 5,1 & 24,9 & 0,3 & 1,2 & 8,8 & 450 & 0 \\
\hline 100 & gr. & sandia. & 28,4 & 0,6 & 0,3 & 5,6 & 0,4 & 0,1 & 0 & 0,1 & 0 & 6,7 & 0,3 & 1,5 & 9,2 & 0,2 & 0,4 & 2 & 100 & 11 \\
\hline \multirow[t]{3}{*}{200} & gr. & $\begin{array}{l}\text { sopa } \\
\text { jardinera } \\
\text { para }\end{array}$ & 704 & 22,4 & 11 & 123,8 & 10 & 5 & 4,1 & 1,5 & 0 & 48,6 & 4,4 & 32 & 64,6 & 2,3 & 7 & 638,4 & 414,6 & 0 \\
\hline & & Total. & 953,2 & 45,6 & 16,4 & 149,5 & & & & & & & & & & & & & & \\
\hline & & $\begin{array}{l}\text { Total } \\
\text { día. }\end{array}$ & 2810 & 157,3 & 37,6 & 444,3 & 37 & 10,9 & 13,4 & 8,6 & 205,3 & 685,1 & 25,7 & 118,1 & 453,6 & 14,7 & 316,1 & 4420 & 4696,3 & 139,9 \\
\hline
\end{tabular}




\section{B. Día 2.}

\begin{tabular}{|c|c|c|c|c|c|c|c|c|c|c|c|c|c|c|c|c|c|c|c|c|}
\hline CANT & UND. & $\begin{array}{l}\text { NOMBR } \\
\text { E }\end{array}$ & KCAL & PROT. & $\begin{array}{l}\text { GRAS } \\
\text { AS }\end{array}$ & $\mathrm{HC}$ & Fibra & AGS g & AGM g & AGP g & $\begin{array}{l}\text { Colest } \\
\text { erol mg }\end{array}$ & $\begin{array}{l}\text { Calcio } \\
\text { mg }\end{array}$ & $\begin{array}{l}\text { Hierro } \\
\text { mg }\end{array}$ & $\begin{array}{l}\text { Yodo } \\
\text { mg }\end{array}$ & $\begin{array}{l}\text { Magne } \\
\text { sio mg }\end{array}$ & $\begin{array}{l}\text { Zinc } \\
\text { mg }\end{array}$ & $\begin{array}{l}\text { Seleni } \\
\text { o mg }\end{array}$ & $\begin{array}{l}\text { Sodio } \\
\text { mg }\end{array}$ & $\begin{array}{l}\text { Potasi } \\
\text { o mg }\end{array}$ & $\begin{array}{l}\text { Fosfor } \\
\text { o mg }\end{array}$ \\
\hline \multicolumn{21}{|c|}{ 09:00 - Desayuno } \\
\hline 150 & & platano. & 142,5 & 1,6 & 0,4 & 31,2 & 3,8 & 0,2 & 0,1 & 0,1 & 0 & 11 & 0,9 & 3,6 & 54,6 & 0,3 & 2,1 & 1,5 & 555 & 21 \\
\hline 100 & & $\begin{array}{l}\text { leche de } \\
\text { vaca } \\
\text { desnatad }\end{array}$ & 37 & 3,9 & 0,2 & 4,9 & 0 & 0,1 & 0,1 & 0 & 2,6 & 120,9 & 0,1 & 11,1 & 28,6 & 0,5 & 1,6 & 53 & 150 & 0 \\
\hline 50 & gr. & $\begin{array}{l}\text { cereales } \\
\text { con base } \\
\text { de maiz. }\end{array}$ & 188 & 4 & 0,4 & 41,5 & 1,2 & 0,1 & 0,1 & 0,1 & 0 & 5 & 4 & 2,5 & 7,5 & 0,1 & 1,3 & 50 & 50 & 0 \\
\hline 50 & gr. & $\begin{array}{l}\text { mermela } \\
\text { da de } \\
\text { albaricoa }\end{array}$ & 129,1 & 0,2 & 0,1 & 31,6 & 0,6 & 0 & 0,1 & 0 & 0 & 10 & 0,2 & 1,4 & 2 & 0 & 1 & 20 & 38,5 & 0 \\
\hline \multirow[t]{2}{*}{100} & gr. & $\begin{array}{l}\text { pan } \\
\text { blanco } \\
\text { sin sal. }\end{array}$ & 265 & 8 & 1,1 & 53,9 & 3,5 & 0,2 & 0,1 & 0,4 & 0 & 20 & 1,7 & 5 & 26 & 0,6 & 22,6 & 2 & 100 & 0 \\
\hline & & Total. & 761,6 & 17,7 & 2,2 & 163,1 & & & & & & & & & & & & & & \\
\hline \multicolumn{21}{|c|}{ 12:00 - Media mañana } \\
\hline 80 & gr. & gelatina. & 270,4 & 67,5 & 0 & 0 & 0 & 0 & 0 & 0 & 0 & 8,8 & 0 & 4,8 & 8,8 & 0,2 & 0 & 25,6 & 17,6 & 0 \\
\hline 100 & gr. & pasa. & 309 & 2,5 & 0,5 & 69,3 & 6,5 & 0,2 & 0,1 & 0,1 & 0 & 80 & 2,3 & 2 & 41 & 0,2 & 7,3 & 21 & 782 & 62 \\
\hline \multirow[t]{2}{*}{125} & gr. & $\begin{array}{l}\text { yogur } \\
\text { desnatad } \\
\text { o natural. }\end{array}$ & 56,1 & 5,3 & 0,4 & 7,9 & 0 & 0,1 & 0,2 & 0 & 1,2 & 175 & 0,1 & 6,6 & 17,1 & 0,6 & 1,2 & 71,2 & 233,8 & 25 \\
\hline & & Total. & 635,5 & 75,3 & 0,9 & 77,2 & & & & & & & & & & & & & & \\
\hline \multicolumn{21}{|c|}{ 15:00 - Almuerzo } \\
\hline 30 & gr. & $\begin{array}{l}\text { tomate } \\
\text { triturado. }\end{array}$ & 11,4 & 0,7 & 0,2 & 1,7 & 0,4 & 0 & 0 & 0,1 & 0 & 18 & 0,3 & 0,7 & 9,6 & 0,1 & 0,2 & 177 & 348 & 0 \\
\hline 150 & gr. & naranja. & 68,2 & 1,3 & 0,3 & 13,4 & 3,4 & 0 & 0,1 & 0,1 & 0 & 61,5 & 0,7 & 3,2 & 22,8 & 0,2 & 1,8 & 2,1 & 247,5 & 7,5 \\
\hline 150 & gr. & $\begin{array}{l}\text { pechuga } \\
\text { de pollo. }\end{array}$ & 217,5 & 33,3 & 9,3 & 0 & 0 & 2,9 & 2,9 & 2,3 & 93 & 21 & 1,6 & 10,4 & 31,5 & 1,2 & 9,8 & 99 & 396 & 0 \\
\hline 50 & gr. & lechuga. & 9,8 & 0,7 & 0,3 & 0,7 & 0,8 & 0,1 & 0 & 0,2 & 0 & 17,4 & 0,5 & 1,5 & 4,4 & 0,1 & 0,5 & 1,5 & 110 & 0 \\
\hline 100 & gr. & pasta. & 359 & 12,8 & 1,6 & 70,9 & 5 & 0,2 & 0,2 & 0,6 & 0 & 24 & 1,8 & 10 & 48 & 1,2 & 62,2 & 7 & 236 & 0 \\
\hline 150 & gr. & $\begin{array}{l}\text { clara de } \\
\text { huevo. }\end{array}$ & 73,6 & 16,7 & 0,3 & 1 & 0 & 0 & 0 & 0 & 0 & 16,5 & 0,3 & 10,2 & 18 & 0 & 8,1 & 255 & 231 & 0 \\
\hline 80 & gr. & tomate. & 17,7 & 0,7 & 0,2 & 2,8 & 1,1 & 0 & 0 & 0,1 & 0 & 8,5 & 0,6 & 1,8 & 6,6 & 0,1 & 0,8 & 7,2 & 193,6 & 19,2 \\
\hline \multirow[t]{2}{*}{50} & gr. & pepino. & 6,6 & 0,3 & 0,1 & 1 & 0,4 & 0 & 0 & 0 & 0 & 9,2 & 0,1 & 0,2 & 3,6 & 0,1 & 0,4 & 1,5 & 70 & 5,5 \\
\hline & & Total. & 763,8 & 66,5 & 12,3 & 91,5 & & & & & & & & & & & & & & \\
\hline \multicolumn{21}{|c|}{18.00 - Merienda } \\
\hline 120 & gr. & $\begin{array}{l}\text { pera en } \\
\text { almibar. }\end{array}$ & 83,2 & 0,3 & 0,1 & 19,3 & 1,8 & 0 & 0 & 0 & 0 & 8,4 & 0,5 & 1,2 & 4,8 & 0,1 & 0,2 & 7,3 & 78 & 3,5 \\
\hline 50 & gr. & $\begin{array}{l}\text { cereales } \\
\text { con base } \\
\text { de arroz. }\end{array}$ & 184 & 7 & 0,5 & 37 & 1,8 & 0,2 & 0,1 & 0,2 & 0 & 30 & 11,6 & 2,5 & 25 & 1 & 16 & 350 & 150 & 0 \\
\hline \multirow[t]{2}{*}{100} & gr. & $\begin{array}{l}\text { leche de } \\
\text { vaca } \\
\text { desnatad }\end{array}$ & 37 & 3,9 & 0,2 & 4,9 & 0 & 0,1 & 0,1 & 0 & 2,6 & 120,9 & 0,1 & 11,1 & 28,6 & 0,5 & 1,6 & 53 & 150 & 0 \\
\hline & & Total. & 304,2 & 11,2 & 0,8 & 61,2 & & & & & & & & & & & & & & \\
\hline \multicolumn{21}{|c|}{ 21:00 Cena } \\
\hline 150 & gr. & breca. & 111,9 & 23,1 & 1,5 & 1,5 & 0 & 0,4 & 0,3 & 0,4 & 72 & 45 & 1,2 & 10,5 & 37,5 & 0,8 & 67,5 & 211,5 & 474 & 0 \\
\hline 100 & gr. & $\begin{array}{l}\text { patata } \\
\text { nueva. }\end{array}$ & 73,6 & 2,3 & 0,1 & 14,8 & 2,1 & 0 & 0 & 0,1 & 0 & 6,4 & 0,4 & 2,6 & 21 & 0,3 & 1,5 & 2,7 & 418 & 9,7 \\
\hline 150 & gr. & $\begin{array}{l}\text { judia } \\
\text { verde } \\
\text { conaelad }\end{array}$ & 54,6 & 2,8 & 1,4 & 5,4 & 4,8 & 0,4 & 0,2 & 0,6 & 0 & 69,9 & 0,9 & 0,8 & 29,4 & 0,4 & 1,8 & 12 & 240 & 0 \\
\hline \multirow[t]{3}{*}{200} & gr. & kiwi. & 103,6 & 2 & 1,6 & 18,2 & 4,2 & 0,2 & 0,2 & 0,8 & 0 & 68,2 & 0,7 & 0,7 & 29,9 & 0,3 & 1,2 & 8 & 580 & 0 \\
\hline & & Total. & 343,7 & 30,2 & 4,6 & 39,9 & & & & & & & & & & & & & & \\
\hline & & Total día & 2809 & 200,9 & 20,8 & 432,9 & 41,4 & 5,4 & 4,9 & 6,2 & 171,4 & 955,6 & 30,6 & 104,4 & 506,3 & 8,9 & 210,7 & 1439 & 5849 & 153,4 \\
\hline
\end{tabular}




\section{Día 3.}

CANT UND. NOMBR KCAL PROT. GRAS HC Fibra AGS g AGM g AGPg Colest Calcio Hierro Yodo Magne Zinc Seleni Sodio Potasi Fosforo

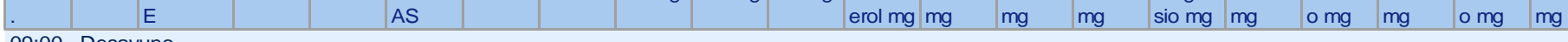
09:00 - Desayuno

\begin{tabular}{|c|c|c|c|c|c|c|c|c|c|c|c|c|c|c|c|c|c|c|c|}
\hline 80 gr. & platano. & 76 & 0,8 & 0,2 & 16,6 & 2 & 0,1 & 0 & 0,1 & 0 & 5,8 & 0,5 & 1,9 & 29,1 & 0,2 & 1,1 & 0,8 & 296 & 11,2 \\
\hline 60 & $\begin{array}{l}\text { pechuga } \\
\text { de pavo }\end{array}$ & 48,6 & 10,7 & 0,3 & 0,8 & & & & & & & & & & & & & & \\
\hline $80 \mathrm{gr}$. & $\begin{array}{l}\text { pan } \\
\text { blanco } \\
\text { sin sal. }\end{array}$ & 212 & 6,4 & 0,9 & 43,1 & 2,8 & 0,2 & 0,1 & 0,3 & 0 & 16 & 1,4 & 4 & 20,8 & 0,5 & 18,1 & 1,6 & 80 & 0 \\
\hline $80 \mathrm{gr}$. & $\begin{array}{l}\text { zumo de } \\
\text { manzana }\end{array}$ & 38,8 & 0 & 0,1 & 9,5 & 0 & 0 & 0 & 0 & 0 & 5,5 & 0,2 & 0,8 & 3,4 & 0,1 & 0,1 & 1,8 & 92,8 & 8 \\
\hline 150 gr. & $\begin{array}{l}\text { leche de } \\
\text { vaca } \\
\text { desnatad }\end{array}$ & 55,5 & 5,8 & 0,3 & 7,4 & 0 & 0,1 & 0,1 & 0 & 3,9 & 181,4 & 0,1 & 16,6 & 42,9 & 0,8 & 2,4 & 79,5 & 225 & 0 \\
\hline $50 \mathrm{gr}$. & $\begin{array}{l}\text { cereales } \\
\text { con base } \\
\text { de arroz. }\end{array}$ & 194 & 3,5 & 0,8 & 43 & 0,5 & 0,3 & 0,1 & 0,3 & 0 & 5 & 4 & 2,5 & 20 & 0,5 & 7,7 & 350 & 70 & 0 \\
\hline & Total. & 624,9 & 27,2 & 2,6 & 120,4 & & & & & & & & & & & & & & \\
\hline
\end{tabular}

\begin{tabular}{|c|c|c|c|c|c|c|c|c|c|c|c|c|c|c|c|c|c|c|}
\hline \multicolumn{19}{|c|}{ 2:00 - Media mañana } \\
\hline $25 \mathrm{gr}$. & $\begin{array}{l}\text { barita de } \\
\text { cereales }\end{array}$ & 98 & 2 & 1,2 & 19,5 & 0,4 & 0,5 & 0 & 0 & 0 & 0 & 2,8 & 0 & 0 & 0 & 0 & 0,1 & 0 \\
\hline 100 gr. & gelatina. & 338 & 84,4 & 0 & 0 & 0 & 0 & 0 & 0 & 0 & 11 & 0 & 6 & 11 & 0,2 & 0 & 32 & 22 \\
\hline
\end{tabular}

\begin{tabular}{|c|c|c|c|c|c|c|c|c|c|c|c|c|c|c|c|c|c|c|c|}
\hline & Total. & 436 & 86,4 & 1,2 & 19,5 & & & & & & & & & & & & & & \\
\hline \multicolumn{20}{|c|}{ 15:00 - Almuerzo } \\
\hline $40 \mathrm{gr}$. & $\begin{array}{l}\text { zanahori } \\
\text { a. }\end{array}$ & 15,8 & 0,5 & 0,1 & 2,8 & 1 & 0 & 0 & 0 & 0 & 10,9 & 0,2 & 2,6 & 4,5 & 0,1 & 0,5 & 24,4 & 128,4 & 7,6 \\
\hline $5 \mathrm{gr}$. & vinagre. & 0,2 & 0 & 0 & 0 & 0 & 0 & 0 & 0 & 0 & 0,8 & 0 & 0 & 1,1 & 0 & 0 & 1 & 4,4 & 0 \\
\hline $90 \mathrm{gr}$. & tomate. & 20 & 0,8 & 0,2 & 3,2 & 1,3 & 0 & 0 & 0,1 & 0 & 9,5 & 0,6 & 2 & 7,5 & 0,1 & 0,9 & 8,1 & 217,8 & 21,6 \\
\hline $40 \mathrm{gr}$. & $\begin{array}{l}\text { remolach } \\
\text { a. }\end{array}$ & 18,4 & 0,6 & 0 & 3,4 & 1 & 0 & 0 & 0 & 0 & 6,8 & 0,4 & 0,2 & 8,4 & 0,1 & 0,2 & 23,2 & 162,8 & 4,8 \\
\hline $3 \mathrm{gr}$. & $\begin{array}{l}\text { aceite de } \\
\text { oliva } \\
\text { viraen }\end{array}$ & 27 & 0 & 3 & 0 & 0 & 0,4 & 2,1 & 0,3 & 0 & 0 & 0 & 0 & 0 & 0 & 0 & 0 & 0 & 0 \\
\hline 100 gr. & $\begin{array}{l}\text { pechuga } \\
\text { de pavo. }\end{array}$ & 105 & 24,1 & 1 & 1 & 0 & 0,4 & 0,2 & 0,2 & 45 & 8 & 1 & 2 & 20 & 1,8 & 22,4 & 46 & 333 & 0 \\
\hline $60 \mathrm{gr}$. & $\begin{array}{l}\text { gamba } \\
\text { roja. }\end{array}$ & 56,5 & 10,8 & 1,1 & 0,9 & 0 & 0,2 & 0,2 & 0,4 & 111 & 69 & 2 & 54 & 41,4 & 0,7 & 14,6 & 183 & 132,6 & 0 \\
\hline $150 \mathrm{gr}$. & $\begin{array}{l}\text { pera en } \\
\text { almibar. }\end{array}$ & 104 & 0,4 & 0,2 & 24,2 & 2,2 & 0 & 0 & 0 & 0 & 10,5 & 0,6 & 1,5 & 6 & 0,2 & 0,3 & 9,2 & 97,5 & 4,4 \\
\hline $150 \mathrm{gr}$. & arroz. & 546 & 10 & 1,4 & 122,4 & 2,1 & 0,3 & 0,3 & 0,5 & 0 & 21 & 1,2 & 21 & 46,5 & 2,2 & 10,5 & 5,8 & 163,5 & 75 \\
\hline \multirow[t]{2}{*}{$50 \mathrm{gr}}$. & lechuga. & 9,8 & 0,7 & 0,3 & 0,7 & 0,8 & 0,1 & 0 & 0,2 & 0 & 17,4 & 0,5 & 1,5 & 4,4 & 0,1 & 0,5 & 1,5 & 110 & 0 \\
\hline & Total. & 902,7 & 47,9 & 7,3 & 158,6 & & & & & & & & & & & & & & \\
\hline \multicolumn{20}{|c|}{ !8:00 - Merienda } \\
\hline $80 \mathrm{gr}$. & $\begin{array}{l}\text { atun al } \\
\text { natural. }\end{array}$ & 79,5 & 18,8 & 0,5 & 0 & 0 & 0,2 & 0,1 & 0,2 & 40,8 & 22,4 & 0,8 & 10,4 & 21,6 & 0,6 & 64,3 & 256 & 184 & 0 \\
\hline \multirow[t]{2}{*}{$50 \mathrm{gr}}$. & $\begin{array}{l}\text { pan } \\
\text { blanco } \\
\text { sin sal. }\end{array}$ & 132,5 & 4 & 0,6 & 27 & 1,8 & 0,1 & 0 & 0,2 & 0 & 10 & 0,8 & 2,5 & 13 & 0,3 & 11,3 & 1 & 50 & 0 \\
\hline & Total. & 212 & 22,8 & 1,1 & 27 & & & & & & & & & & & & & & \\
\hline \multicolumn{20}{|c|}{ 21:00 Cena } \\
\hline $100 \mathrm{gr}$. & $\begin{array}{l}\text { piña en } \\
\text { su jugo. }\end{array}$ & 42,9 & 0,4 & 0,1 & 9,7 & 0,8 & 0,1 & 0 & 0 & 0 & 15 & 0,3 & 1 & 13 & 0,1 & 0,4 & 4,6 & 116 & 0 \\
\hline $120 \mathrm{gr}$. & $\begin{array}{l}\text { sopa } \\
\text { jardinera } \\
\text { para }\end{array}$ & 422,4 & 13,4 & 6,6 & 74,3 & 6 & 3 & 2,4 & 0,9 & 0 & 29,2 & 2,7 & 19,2 & 38,8 & 1,4 & 4,2 & 383 & 248,8 & 0 \\
\hline \multirow[t]{3}{*}{$90 \mathrm{gr}}$. & $\begin{array}{l}\text { huevo } \\
\text { de } \\
\text { gallina. }\end{array}$ & 145,8 & 11,4 & 10,9 & 0,6 & 0 & 3 & 4,4 & 1,6 & 369 & 50,6 & 2 & 11,4 & 10,9 & 1,8 & 9 & 129,6 & 132,3 & 99 \\
\hline & Total & 611,1 & 25,2 & 17,6 & 84,6 & & & & & & & & & & & & & & \\
\hline & Total día & 2787 & 209,5 & 29,8 & 410,1 & 22,7 & 9 & 10 & 5,3 & 569,7 & 505,8 & 22,1 & 161,1 & 364,3 & 11,8 & 168,5 & 1542 & 2867 & 231,6 \\
\hline
\end{tabular}




\section{Día 4.}

\begin{tabular}{|c|c|c|c|c|c|c|c|c|c|c|c|c|c|c|c|c|c|c|c|}
\hline 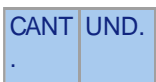 & $\begin{array}{l}\text { NOMBR } \\
E\end{array}$ & KCAL & PROT. & $\begin{array}{l}\text { GRAS } \\
\text { AS }\end{array}$ & $\mathrm{HC}$ & Fibra & AGS g & AGM g & AGP g & $\begin{array}{l}\text { Colest } \\
\text { erol mg }\end{array}$ & \begin{tabular}{l|l} 
Calcio & 1 \\
$m g$ & 1
\end{tabular} & $\begin{array}{l}\text { Hierro } \\
\text { mg }\end{array}$ & $\begin{array}{l}\text { Yodo } \\
\text { mg }\end{array}$ & $\begin{array}{l}\text { Magne } \\
\text { sio mg }\end{array}$ & $\begin{array}{l}\text { Zinc } \\
\text { mg }\end{array}$ & $\begin{array}{l}\text { Seleni } \\
\text { o mg }\end{array}$ & $\begin{array}{l}\text { Sodio } \\
m g\end{array}$ & $\begin{array}{l}\text { Potasio } \\
\text { mg }\end{array}$ & $\begin{array}{l}\text { Fosforo } \\
\text { mg }\end{array}$ \\
\hline \multicolumn{20}{|c|}{ 08:00 - Desayuno } \\
\hline 150 gr. & $\begin{array}{l}\text { zumo de } \\
\text { naranja. }\end{array}$ & 65,3 & 1 & 0,3 & 14,1 & 1 & 0 & 0,1 & 0,1 & 0 & 16,2 & 0,2 & 1,5 & 16,3 & 0,2 & 1,5 & 1,5 & 214,5 & 1,4 \\
\hline $150 \mathrm{gr}$. & $\begin{array}{l}\text { leche de } \\
\text { vaca } \\
\text { desnatad }\end{array}$ & 55,5 & 5,8 & 0,3 & 7,4 & 0 & 0,1 & 0,1 & 0 & 3,9 & 181,4 & 0,1 & 16,6 & 42,9 & 0,8 & 2,4 & 79,5 & 225 & 0 \\
\hline $50 \mathrm{gr}$. & $\begin{array}{l}\text { pan } \\
\text { integral. }\end{array}$ & 110,5 & 3,5 & 1,4 & 19 & 3,8 & 0,3 & 0,2 & 0,6 & 0 & 27 & 1,4 & 0,5 & 38 & 0,9 & 17,5 & 275 & 115 & 0 \\
\hline 100 gr. & $\begin{array}{l}\text { albaricoq } \\
\text { ue seco } \\
\text { oreiones. }\end{array}$ & 283 & 3,4 & 0,5 & 62,6 & 7,3 & 0 & 0,1 & 0,1 & 0 & 55 & 2,7 & 1 & 32 & 0,4 & 2,2 & 10 & 1162 & 0 \\
\hline 80 gr. & $\begin{array}{l}\text { cereales } \\
\text { con base } \\
\text { de maiz. }\end{array}$ & 316 & 4,8 & 2,4 & 68 & 1,6 & 0,3 & 0,8 & 1,3 & 0 & 362,4 & 6,3 & 4 & 16 & 0,4 & 14,5 & 480 & 96 & 0 \\
\hline \multirow[t]{2}{*}{$30 \mathrm{gr}}$. & $\begin{array}{l}\text { jamon } \\
\text { serrano. }\end{array}$ & 40,8 & 6,4 & 1,7 & 0 & 0 & 0,6 & 0,8 & 0,2 & 21,3 & 3,8 & 0,7 & 3,4 & 5,1 & 0,7 & 0 & 702 & 75 & 0 \\
\hline & Total. & 871,1 & 24,9 & 6,6 & 171,1 & & & & & & & & & & & & & & \\
\hline \multicolumn{20}{|c|}{11.00 - Media mañana } \\
\hline 150 gr. & sandia. & 42,6 & 0,9 & 0,4 & 8,4 & 0,6 & 0,2 & 0 & 0,2 & 0 & 10,1 & 0,4 & 2,2 & 13,8 & 0,3 & 0,6 & 3 & 150 & 16,5 \\
\hline \multirow[t]{2}{*}{100 gr. } & gelatina. & 338 & 84,4 & 0 & 0 & 0 & 0 & 0 & 0 & 0 & 11 & 0 & 6 & 11 & 0,2 & 0 & 32 & 22 & 0 \\
\hline & Total. & 380,6 & 85,3 & 0,4 & 8,4 & & & & & & & & & & & & & & \\
\hline \multicolumn{20}{|c|}{ 14:00 - Almuerzo } \\
\hline 100 gr. & $\begin{array}{l}\text { fresa y } \\
\text { freson. }\end{array}$ & 32,2 & 0,8 & 0,4 & 5,5 & 1,7 & 0 & 0,1 & 0,2 & 0 & 21,5 & 0,5 & 2,7 & 13,3 & 0,2 & 1,3 & 1,4 & 161 & 16 \\
\hline 100 gr. & $\begin{array}{l}\text { crema } \\
\text { desecad } \\
\text { a de }\end{array}$ & 426 & 8 & 15,5 & 62,3 & 2,4 & 8,5 & 5,9 & 0,3 & 1 & 25,3 & 1,9 & 90,8 & 49,3 & 2,3 & 0,7 & 439 & 93,2 & 0 \\
\hline $50 \mathrm{gr}$. & $\begin{array}{l}\text { pan } \\
\text { blanco } \\
\text { sin sal. }\end{array}$ & 132,5 & 4 & 0,6 & 27 & 1,8 & 0,1 & 0 & 0,2 & 0 & 10 & 0,8 & 2,5 & 13 & 0,3 & 11,3 & 1 & 50 & 0 \\
\hline \multirow[t]{2}{*}{100 gr. } & $\begin{array}{l}\text { paella de } \\
\text { marisco } \\
\text { conaelad }\end{array}$ & 124 & 3,6 & 0,6 & 25,1 & 2 & 0,2 & 0,2 & 0,1 & 17 & 20,3 & 0,7 & 11,2 & 23,2 & 0,2 & 10,7 & 429,3 & 214,3 & 0 \\
\hline & Total. & 714,7 & 16,4 & 17,1 & 119,9 & & & & & & & & & & & & & & \\
\hline \multicolumn{20}{|c|}{ 17:00 - Merienda } \\
\hline 100 gr. & $\begin{array}{l}\text { pan } \\
\text { blanco } \\
\text { sin sal. }\end{array}$ & 265 & 8 & 1,1 & 53,9 & 3,5 & 0,2 & 0,1 & 0,4 & 0 & 20 & 1,7 & 5 & 26 & 0,6 & 22,6 & 2 & 100 & 0 \\
\hline \multirow[t]{2}{*}{80 gr. } & $\begin{array}{l}\text { atun al } \\
\text { natural. }\end{array}$ & 79,5 & 18,8 & 0,5 & 0 & 0 & 0,2 & 0,1 & 0,2 & 40,8 & 22,4 & 0,8 & 10,4 & 21,6 & 0,6 & 64,3 & 256 & 184 & 0 \\
\hline & Total. & 344,5 & 26,8 & 1,6 & 53,9 & & & & & & & & & & & & & & \\
\hline \multicolumn{20}{|l|}{ 21:00 - Cena } \\
\hline $50 \mathrm{gr}$. & $\begin{array}{l}\text { pan } \\
\text { blanco } \\
\text { sin sal. }\end{array}$ & 132,5 & 4 & 0,6 & 27 & 1,8 & 0,1 & 0 & 0,2 & 0 & 10 & 0,8 & 2,5 & 13 & 0,3 & 11,3 & 1 & 50 & 0 \\
\hline $70 \mathrm{gr}$. & espinaca & 14,5 & 1,8 & 0,2 & 0,4 & 1,8 & 0 & 0 & 0,1 & 0 & 81,9 & 1,9 & 8,4 & 42 & 0,4 & 0,6 & 48,3 & 387,8 & 52,5 \\
\hline 175 gr. & $\begin{array}{l}\text { pechuga } \\
\text { de pavo. }\end{array}$ & 183,8 & 42,2 & 1,7 & 1,8 & 0 & 0,6 & 0,4 & 0,4 & 78,8 & 14 & 1,8 & 3,5 & 35 & 3,2 & 39,2 & 80,5 & 582,8 & 0 \\
\hline 175 gr. & $\begin{array}{l}\text { piña en } \\
\text { su jugo. }\end{array}$ & 75,1 & 0,7 & 0,2 & 17 & 1,4 & 0,1 & 0 & 0,1 & 0 & 26,2 & 0,5 & 1,8 & 22,8 & 0,1 & 0,7 & 8 & 203 & 0 \\
\hline \multirow[t]{3}{*}{$150 \mathrm{gr}}$. & $\begin{array}{l}\text { clara de } \\
\text { huevo. }\end{array}$ & 73,6 & 16,7 & 0,3 & 1 & 0 & 0 & 0 & 0 & 0 & 16,5 & 0,3 & 10,2 & 18 & 0 & 8,1 & 255 & 231 & 0 \\
\hline & Total. & 479,5 & 65,4 & 3 & 47,2 & & & & & & & & & & & & & & \\
\hline & $\begin{array}{l}\text { Total } \\
\text { día. }\end{array}$ & 2790 & 218,8 & 28,7 & 400,5 & 30,7 & 11,5 & 8,9 & 4,7 & 162,8 & 935 & 23,5 & 184,2 & 452,3 & 12,1 & 209,5 & 3105 & 4316,6 & 86,4 \\
\hline
\end{tabular}




\section{4.-BIBLIOGRAFÍA}

Ainsworth, B. E. et al. (2011). 2011 compendium of physical activities: a second update of codes and MET values. Medicine and Science in Sports and Exercise, 43(8), 1575-1581.

Fernández, M. D. (2003) Nutrición, alimentación y manipulación de la dieta del deportista, 179-219.

Martínez-Sanz, J. M, Urdampilleta, A. y Guerrero, J. Composición corporal y somatotipo en nadadores adolescentes del club de natación Pilar De la horadada. Martinez, V. (Comp). IV congreso internacional universitario de las ciencias de la salud y el deporte. (2010). 284-289.

Necesidades energéticas, hídricas y nutricionales en el deporte. European Journal of Human Movement, 31 (37-52).

Obregón, M.J. (2009). Papel de la termogénesis en el balance energético. Monografías de la Real Academia Nacional de Farmacia, Monografía XVIII.

Palavecino, N. (2002). Nutrición para el alto rendimiento. Córdoba.

Paz, R. H. H. (2006). La Nutrición en la Natación. G-SE Standard.

Martínez-Sanz, J., Urdampilleta, A., \& Mielgo- Ayuso, J. (2013).

Paz Lasanta I. A. (2004). Fisiología Intramuscular. Editorial Gente Nueva. La Habana.

Palacios, N., Montalvo, Z., \& Ribas, A. M. (2009). Alimentación, Nutrición e Hidratación en el Deporte. Madrid: Consejo Superior de Deporte.

Ramírez, F. (2006). Conferencia la Nutrición en la Natación. Curso Bases 
del entrenamiento de la natación.

Saldivar l. et al. (2000). Manual Práctico de la Natación. Universidad de Oriente. Santiago de Cuba. 